\title{
The Zonal Dipole Pattern of Tropical Cyclone Genesis in the Indian Ocean Influenced by the Tropical Indo-Pacific Ocean Sea Surface Temperature Anomalies
}

\author{
JUNPENG YUAN \\ Key Laboratory of Atmospheric Environment and Processes in the Boundary Layer over the Low-Latitude Plateau Region, \\ Department of Atmospheric Sciences, Yunnan University, Kunming, China \\ YONG GAO \\ Key Laboratory of Atmospheric Environment and Processes in the Boundary Layer over the Low-Latitude Plateau \\ Region, Department of Atmospheric Sciences, Yunnan University, Kunming, and Meteorological Bureau of \\ Tibet Autonomous Region, Lhasa, China \\ DiAN FENG AND YALI YANG \\ Key Laboratory of Atmospheric Environment and Processes in the Boundary Layer over the Low-Latitude \\ Plateau Region, Department of Atmospheric Sciences, Yunnan University, Kunming, China
}

(Manuscript received 16 January 2019, in final form 24 June 2019)

\begin{abstract}
From a basinwide perspective, the dominant mode of Indian Ocean tropical cyclone genesis (TCG) in September-November (SON) shows an equatorially symmetric east-west zonal dipole pattern, which can explain approximately $13 \%$ of the SON TCG variance. This zonal dipole TCG pattern is significantly related to the tripole pattern of the sea surface temperature anomalies (SSTAs) in the tropical Indo-Pacific Ocean (IPT). The IPT, which is a combined interbasin mode and presents a dipole pattern of SSTAs in the tropical Indian Ocean and El Niño-like SSTAs in the tropical Pacific Ocean, can influence the local Walker circulation and zonal dipole TCG pattern over the tropical Indian Ocean. Associated with a positive IPT phase, abnormal ascending (descending) motions are induced and favorable for more (less) water vapor transport to the lowermiddle level in the western (eastern) tropical Indian Ocean; significant anticyclonic vorticity anomalies are evoked in the lower level over the eastern tropical Indian Ocean, and weak easterly vertical wind shear appears over the tropical Indian Ocean. Thus, abnormally strong upward motion, abundant water vapor in the lower-middle level, and weak vertical wind shear are favorable for more TCG in the western tropical Indian Ocean, while the combined negative contributions of the vertical motion, lower-level vorticity, and humidity terms result in less TCG in the eastern tropical Indian Ocean.
\end{abstract}

\section{Introduction}

Tropical cyclones (TCs) are among the most destructive weather systems in the world and span the global tropical oceans. The Indian Ocean is one of the oceans prone to TCs. In the northern Indian Ocean, including the Bay of Bengal (BOB) and Arabian Sea (AS), TCs exhibit a unique bimodal seasonal distribution caused by unfavorable environmental conditions during the monsoon season (Li et al. 2013). Peak TC activity occurs during September-November, with a secondary maximum during April-June (Fig. 1a). In the southern Indian Ocean,

Corresponding author: Junpeng Yuan, jpyuan@ynu.edu.cn
TC genesis (TCG) gradually increases in the season of September-November (SON) and reaches the peak season in December-March (Fig. 1b).

The primary source of energy for TCs is the heat transferred from ocean to atmosphere; thus, the local sea thermal states are very important to TC activities (Gray 1968; Rotunno and Emanuel 1987). The Indian Ocean dipole (IOD) mode, of which the sea surface temperature anomalies (SSTAs) vary oppositely between the western and southeastern tropical Indian Ocean, is a distinct mode in the Indian Ocean on interannual time scales (Saji et al. 1999; Webster et al. 1999). Although the SSTAs are asymmetric about the equator in the eastern Indian Ocean during IOD events, 


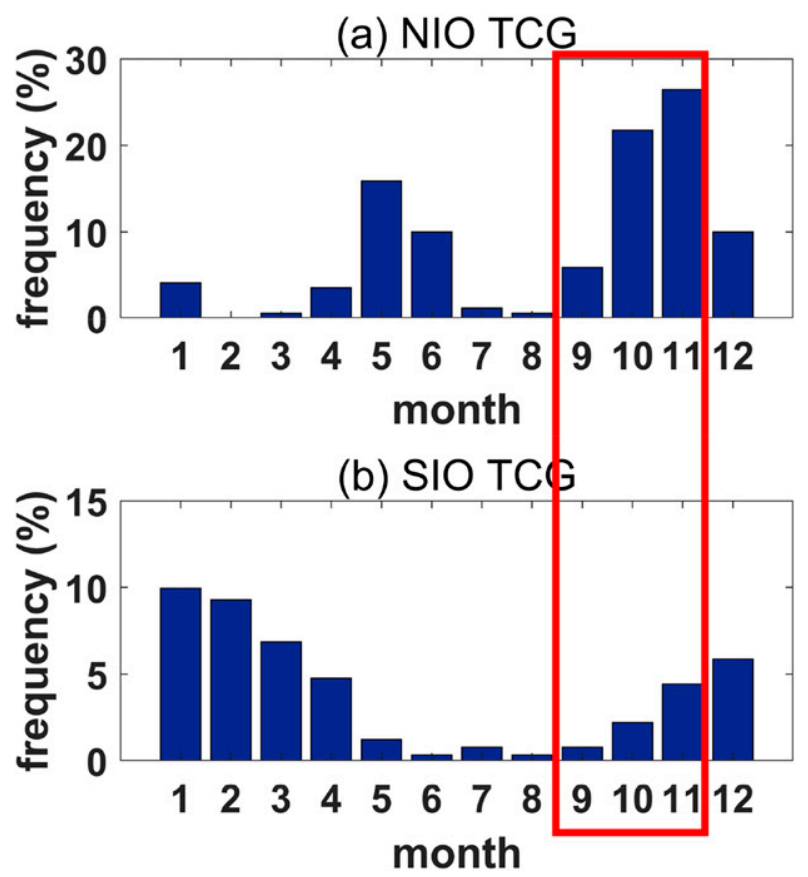

FIG. 1. Monthly frequency distribution of TCG in the (a) northern and (b) southern Indian Ocean during 1981-2015. The red box highlights the season of SON on which this study focuses.

the induced wind curl anomalies are quite symmetric about the equator ( $\mathrm{Li}$ et al. 2003; Schott et al. 2009). By modifying the local thermal states and large-scale atmospheric circulation, the IOD may exert a great influence on TC activities in both the southern and northern Indian Ocean (Singh 2008; Yuan and Cao 2013; $\mathrm{Li}$ et al. 2015; Li et al. 2016). Results of Yuan and Cao (2013) indicate that TC activities in the northern Indian Ocean are closely related to IOD events; that is, fewer (more) TCs occur in the BOB and AS regions during positive (negative) IOD years. Singh (2008) found a significant negative correlation between the SeptemberOctober IOD index and the BOB TC frequency in November and suggested that, with a lead time of one month, the IOD could be a potential predictor of intense cyclones in November over the BOB. By compositing the monthly TC frequencies in positive and negative IOD years, Li et al. $(2015,2016)$ observed that TC frequencies over both the BOB and the southeastern Indian Ocean exhibit significant differences during October-November between positive and negative IOD years.

As a dominant interannual mode in the tropical oceans, El Niño-Southern Oscillation (ENSO) may also exert a remote influence on the genesis, frequency, track, and intensity of TCs over the Indian Ocean, through induced large-scale atmospheric circulation (e.g., Ho et al. 2006; Girishkumar and Ravichandran 2012; Ng and Chan 2012; Felton et al. 2013; Sumesh and
Kumar 2013). Compared with El Niño, La Niña conditions offer a more favorable environment for TC activity over the BOB ( $\mathrm{Ng}$ and Chan 2012; Felton et al. 2013; Mahala et al. 2015), especially in October-December (Girishkumar and Ravichandran 2012; Felton et al. 2013). In addition, Girishkumar et al. (2015) indicated that the ENSO-TC relationship in October-December over the BOB can be modified by the Pacific decadal oscillation, with a more significant relationship in warm Pacific decadal oscillation phases. Balaguru et al. (2016) also showed that ENSO induces a meridional dipole mode of TC activity in the BOB during the premonsoon season of May-June through a modulation of the monsoon circulation. ENSO can also modify TC activity in the southern Indian Ocean (Ho et al. 2006; Werner et al. 2012); more (fewer) TCs occur in the southwestern tropical Indian Ocean during El Niño (La Niña) years (Kuleshov et al. 2008; Ash and Matyas 2012).

Previous works have revealed that TC activities in several regions of the Indian Ocean, such as the BOB and the southwestern and southeastern Indian Ocean, may be influenced by both the local SSTAs in the tropical Indian Ocean and remote SSTAs in the tropical Pacific Ocean. However, these studies focused mainly on the influences of the IOD/ENSO on TC activities in one single sea region of the Indian Ocean. It should be noted that the IOD/ENSO-induced oceanic processes and atmospheric circulation anomalies are significant and widespread in both the northern and southern tropical Indian Oceans. However, the influences of the tropical Indo-Pacific Ocean SSTAs on the TC activities in the whole Indian Ocean on a basinwide scale are as yet unclear. Moreover, there remain some uncertainties over the extent of the IOD/ENSO link to the Indian Ocean TC activities. For example, the BOB TCs are found to be more active in the co-occurrences of La Niña and negative IOD years (Girishkumar and Ravichandran 2012; Mahala et al. 2015). However, composite analysis has shown that the differences of BOB TCG in October-November are significant between the positive and negative IOD years, but not significant between El Niño and La Niña years ( Li et al. 2015). Also, in the southern Indian Ocean, Li et al. (2016) observed that the TC frequency in OctoberNovember is co-affected by El Niño and positive IOD events, but La Niña seems to have limited influence. Liu and Chan (2012) investigated the ENSO/IOD link to the $\mathrm{TC}$ activities in the southern Indo-Pacific Ocean, and suggested that ENSO and the IOD cannot be treated as separate modes. The atmospheric circulation anomalies induced by ENSO and the IOD are difficult to separate completely, especially on an interannual time scale (Saji et al. 1999; Yuan and Li 2008; Xie et al. 2009; 
Girishkumar and Ravichandran 2012). Thus, it is necessary to take the tropical Indo-Pacific Ocean as a whole to investigate its influence on the TCs in the Indian Ocean. This work mainly focuses on the basinwide scale TCG in the Indian Ocean and investigates the relationship between the Indian Ocean TCG and the SSTAs of the entire tropical Indo-Pacific Ocean.

As shown in Fig. 1, TCG in the north Indian Ocean exhibits a bimodal seasonal distribution, comprising $54.4 \%$ and $29.4 \%$ of the total TCG during the peak season of September-November and the secondary maximum during April-June, respectively, whereas in the southern Indian Ocean approximately $7.4 \%$ and $6.3 \%$ of the total TCG occurs during SeptemberNovember and April-June, respectively. For the differences of the seasonal distribution of TCG and background circulations in the northern and southern Indian Ocean, we focus on the season of SON, which is the peak season of TCG in the northern Indian Ocean and the season that TCs begin to be more active in the southern Indian Ocean. SON is also a season of strong atmosphere-ocean interactions in the Indo-Pacific Ocean (Ju et al. 2004; Chen 2011; Lian et al. 2014), when the signals induced by both ENSO and the IOD are strong (Chen 2011; Lian et al. 2014) and may exert great influence on TCG in the Indian Ocean.

This paper is organized as follows: section 2 describes the dataset and methods used for the study. An overview of TCG over the Indian Ocean during 1981-2015 is presented in section 3. Section 4 shows the relationship between the TCG in the Indian Ocean and SSTAs in the tropical Indo-Pacific Ocean. Section 5 investigates the impact of tropical Indo-Pacific Ocean SSTAs on the TCG environments in the Indian Ocean. A summary of our findings is presented in section 6 .

\section{Data and methods}

\section{a. Datasets}

The TC datasets during 1981-2015 are extracted from the Joint Typhoon Warning Center over the northern and southern Indian Ocean (Chu et al. 2002).The present study focuses exclusively on TCs with the maximum sustained wind speeds greater than $34 \mathrm{kt}\left(17 \mathrm{~m} \mathrm{~s}^{-1}\right)$; thus, only tropical storms and typhoons are considered.

The following datasets for the period 1981-2015 are also used: monthly atmospheric data at $0.75^{\circ} \times 0.75^{\circ}$ resolution from the European Centre for MediumRange Weather Forecasts interim reanalysis (ERAInterim; Dee et al. 2011), and monthly SST on a $2^{\circ} \times 2^{\circ}$ grid from version $3 \mathrm{~b}$ of the Extended Reconstructed SST dataset of the National Oceanic and Atmospheric Administration (Smith et al. 2008).

\section{b. The IOD mode index and Niño-3.4 index}

Following Saji et al. (1999), the Indian Ocean dipole mode index (DMI) is defined as the differences of the averaged SON SSTAs between the western $\left(10^{\circ} \mathrm{S}-10^{\circ} \mathrm{N}\right.$, $\left.50^{\circ}-70^{\circ} \mathrm{E}\right)$ and eastern $\left(10^{\circ} \mathrm{S}-0^{\circ}, 90^{\circ}-110^{\circ} \mathrm{E}\right)$ tropical Indian Ocean. For ENSO, the averaged SON SSTAs in the Niño-3.4 region $\left(5^{\circ} \mathrm{N}-5^{\circ} \mathrm{S}, 170^{\circ}-120^{\circ} \mathrm{W}\right)$ are computed to represent the Niño-3.4 index. For ease of comparison, all variables are standardized by first subtracting the mean from the raw data, and then dividing the difference by the standard deviation. All discussion on the various time series is therefore based on standardized values, unless otherwise stated.

\section{c. TC genesis potential index}

Climatologically, cyclone genesis is intimately related to large-scale environmental factors, including low-level relative vorticity, Coriolis forcing, vertical shear of the horizontal winds, the sea surface thermal state, conditional instability through a deep atmospheric layer, and humidity in the lower and middle troposphere (Gray 1968, 1979). Motivated by the work of Gray (1979), Emanuel and Nolan (2004) developed the TC genesis potential index (GPI) to describe quantitatively the influences of large-scale environmental factors on cyclone genesis. Murakami and Wang (2010) further redefined the GPI by explicitly incorporating the vertical motion term to improve the reproducibility of TCG over regions with strong ascending motions. Recently, Wang and Moon (2017) indicated that the vertical motion is a meaningful factor for TCG in the Indian Ocean. Thus, the present study uses the GPI developed by Murakami and Wang (2010) to determine the factors responsible for TCG location changes in the tropical Indian Ocean. The formulation of the GPI is as follows:

GPI

$$
=\left|10^{5} \eta\right|^{3 / 2}\left(\frac{\mathrm{RH}}{50}\right)^{3}\left(\frac{V_{\mathrm{pot}}}{70}\right)^{3}\left(1+0.1 V_{\text {shear }}\right)^{-2}\left(\frac{-\omega+0.1}{0.1}\right),
$$

where $\eta$ is the absolute vorticity $\left(\mathrm{s}^{-1}\right)$ at $850 \mathrm{hPa}, \mathrm{RH}$ is the relative humidity (\%) at $700 \mathrm{hPa}, V_{\text {pot }}$ is the maximum potential intensity $\left(\mathrm{m} \mathrm{s}^{-1}\right), V_{\text {shear }}$ is the magnitude of the vertical zonal wind shear $\left(\mathrm{m} \mathrm{s}^{-1}\right)$ between 200 and $850 \mathrm{hPa}$, and $\omega$ is the vertical pressure velocity (omega; $\mathrm{Pa} \mathrm{s}^{-1}$ ) at $500 \mathrm{hPa}$. The definition of maximum potential intensity is based on Emanuel (1995), and was modified by Bister and Emanuel (1998). A FORTRAN source code for computing the maximum potential intensity is available 
(a)

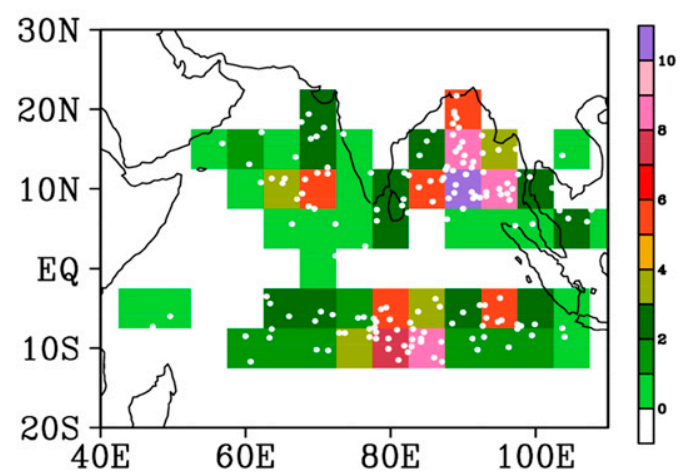

(b)

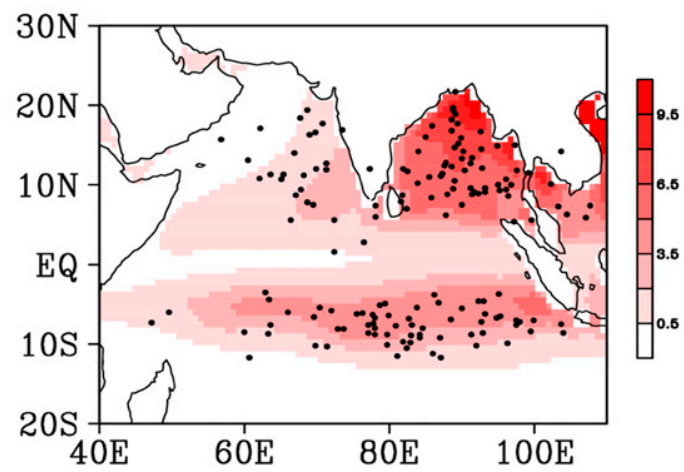

FIG. 2. (a) Geographical distribution of TCG number (shaded) in each $5^{\circ} \times 5^{\circ}$ grid box during $1981-2015$. (b) The distribution of GPI (shaded) during 1981-2015. The dots indicate TCG locations.

online (ftp://texmex.mit.edu/pub/emanuel/TCMAX/pcmin_ revised.f).

To assess quantitatively the individual contributions of each term in Eq. (1) to the total GPI, the GPI change is decomposed using the method of Li et al. (2013) and $\mathrm{Li}$ et al. (2016). The following introduction of the method is derived from Li et al. (2016) with minor modifications. First a natural logarithm is taken on both sides of the GPI formula, and then a total differential is applied to both sides; thus the change of GPI can be separated into five terms, as below:

$$
\begin{aligned}
\delta \mathrm{GPI}= & \alpha_{1} \times \delta \text { Term } 1+\alpha_{2} \times \delta \text { Term } 2+\alpha_{3} \\
& \times \delta \text { Term } 3+\alpha_{4} \times \delta \text { Term } 4+\alpha_{5} \times \delta \text { Term } 5,
\end{aligned}
$$

where

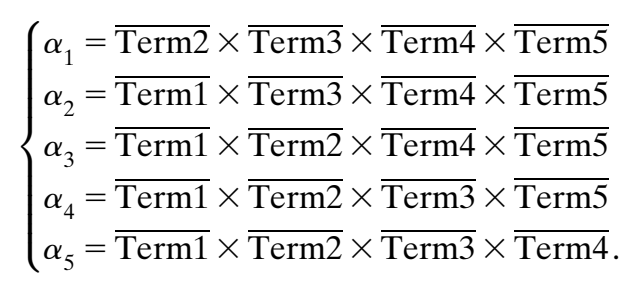

This method shows some skill in the diagnosis of the relative contribution of environmental factors to TCG in both the northern and southern Indian Ocean ( $\mathrm{Li}$ et al. 2013; Li et al. 2015; Li et al. 2016). The present work also applies this GPI quantitative method to assess the contribution of each large-scale factor to TCG.

\section{d. Moisture budget diagnosis}

The moisture tendency equation at a constant pressure level is used to analyze specific processes that cause the specific humidity anomaly (Yanai et al. 1973; Hsu and Li 2012; Li et al. 2013; Li et al. 2016). The tendency equation for the specific humidity anomaly $q^{\prime}$ is written as

$$
\frac{\partial q^{\prime}}{\partial t}=-(\mathbf{V} \nabla q)^{\prime}-\left(\omega \frac{\partial q}{\partial p}\right)^{\prime}-\left(\frac{Q_{2}}{L}\right)^{\prime}
$$

where $q$ is the specific humidity, $\mathbf{V}$ is the horizontal wind vector, $-(\mathbf{V} \nabla q)^{\prime}$ indicates anomalous horizontal moisture advection, $p$ is the pressure, $\omega$ is the vertical pressure velocity, $-[\omega(\partial q / \partial p)]^{\prime}$ denotes anomalous vertical moisture advection, $Q_{2}$ is the atmospheric apparent moisture sink, and $L$ is the latent heat of condensation.

In addition, empirical orthogonal function (EOF) analysis is used to reveal the spatiotemporal characteristics of TCG in the Indian Ocean. Singular value decomposition (SVD) analysis is carried out to verify the relationship between the TCG in the Indian Ocean and SSTAs in the tropical Indo-Pacific Ocean.

Correlation, regression, and composite analysis are also used in this paper. North's significance test (North et al. 1982) is used for significance testing of the EOF and SVD analysis. The two-sided Student's $t$ test, which gives the probability that the means for two groups are statistically different at the $90 \%$ and $95 \%$ confidence levels, is used for significance testing of the composite analysis. Monthly anomalies of all quantities here are computed by removing the climatological monthly means.

\section{Overview of TCG in the Indian Ocean}

During the period 1981-2015, there were a total of 92 and 67 TCs generated in the northern and southern Indian Ocean in SON, respectively. In the northern Indian Ocean, most of the TCs are generated in the BOB and eastern AS. TCs form frequently in the regions of $60^{\circ}$ $100^{\circ} \mathrm{E}$ around $10^{\circ} \mathrm{S}$ in the southern Indian Ocean (Fig. 2a). The frequency of TCG was also counted in each $5^{\circ} \times 5^{\circ}$ box in the Indian Ocean, which measures how frequently TCs are formed within a specific grid 
(a)

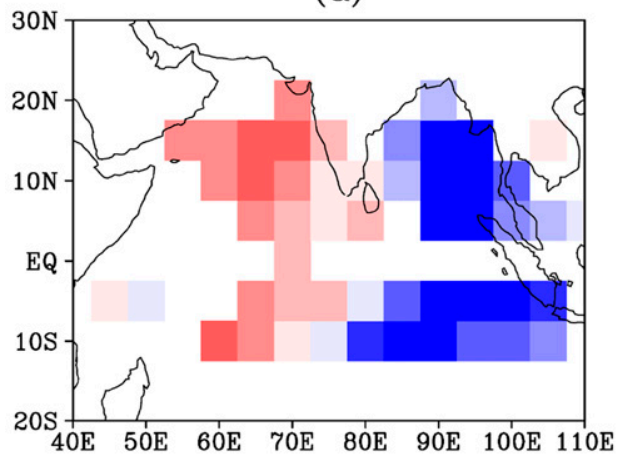

(b)

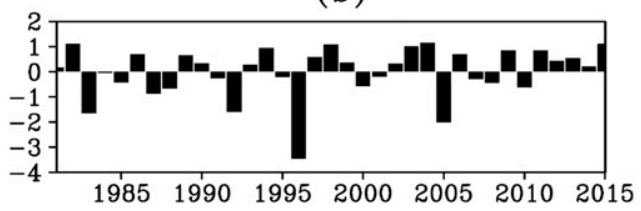

FIG. 3. First empirical orthogonal function (EOF1) mode of SON TCG frequency in the Indian Ocean during 1981-2015: (a) spatial distribution and (b) standard time series.

box. Thus, we can use the TCG number in each box to investigate the spatiotemporal variations of TCG in the Indian Ocean.

EOF analysis is used to reveal the spatiotemporal characteristics of the TCG frequency in the Indian Ocean. The dominant first mode of EOF analysis (EOF1) of TCG shows a zonal dipole variation pattern in both the northern and southern Indian Ocean (Fig. 3a). The frequency of TCG varies oppositely in the east and west parts of the Indian Ocean, with high positive (negative) loadings centered in the AS and southwestern Indian Ocean (BOB and southeastern Indian Ocean). This indicates that TCG in the northern and southern Indian Ocean covaries as an equatorially symmetric east-west zonal dipole pattern. The EOF1 mode explains approximately $13 \%$ of the SON TCG variance. Note that $13 \%$ is not a very big percentage of TCG variance, and may be partly owing to the differences of the TCG seasonal distributions in the northern and southern Indian Ocean (Fig. 1). The North's significance test for the TCG EOF analysis indicates that the EOF1 mode is a clearly independent mode. The time series of the EOF1 mode shows apparent interannual variation (Fig. 3b), with fewer (more) TCG events in the BOB and southeastern Indian Ocean and more (fewer) in the AS and southwestern Indian Ocean during the positive (negative) anomaly years (Fig. 3a). Wavelet analysis indicates that the EOF1 mode varies mainly at a quasi-5-yr scale (figure not shown).

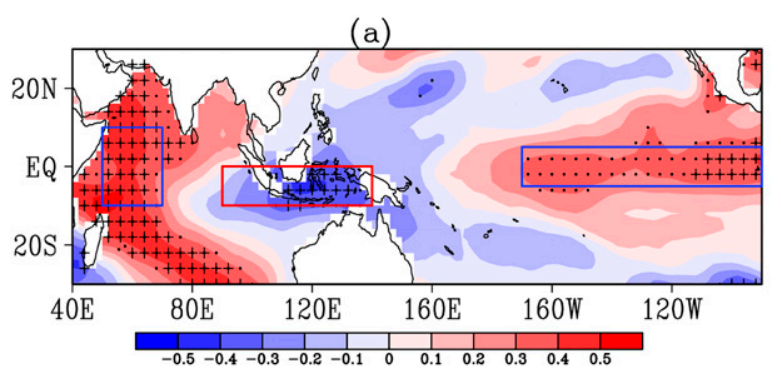

(b)

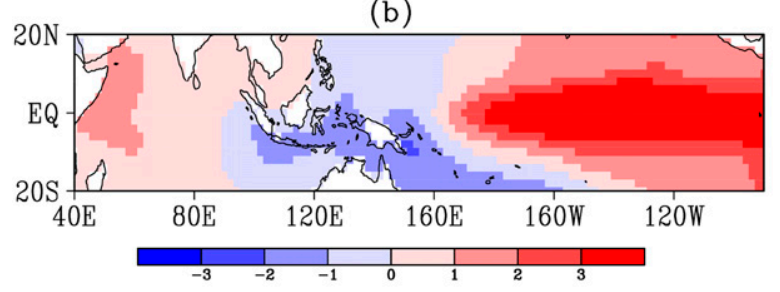

(c)

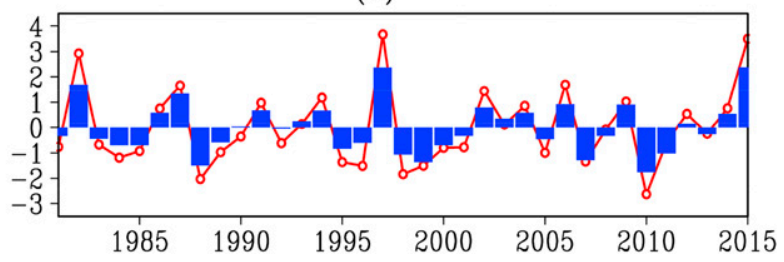

FIG. 4. (a) Correlation coefficients (shaded) of the time series of the Indian Ocean TCG EOF1 mode and SSTAs in the Indo-Pacific Ocean during 1981-2015. The black plus signs or dots indicate that the correlation coefficient passes the significance test at the $95 \%$ or $90 \%$ confidence level, respectively. Also shown are the leading EOF1 modes of the SON SSTAs in the tropical Indo-Pacific Ocean during 1981-2015: (b) spatial distribution and (c) standard time series (the blue bar). The red line in (c) shows the IPT index.

\section{Relationship between the Indian Ocean TCG and tropical Indo-Pacific SSTAs}

The relationships of TCG in the Indian Ocean with the SSTAs of the tropical Indo-Pacific Ocean are investigated in this section. The correlations between the time series of the TCG EOF1 mode and the SSTAs in the tropical Indo-Pacific Ocean show a distinct tripole pattern (Fig. 4a). Significant positive correlations appear in the western tropical Indian Ocean and central-eastern equatorial Pacific Ocean, but negative correlations are present in the Maritime Continent regions. It appears that the zonal dipole pattern of TCG in the Indian Ocean is significantly connected with the combined effects of the SSTAs in both the tropical Indian and Pacific Oceans. In Fig. 4a, the distribution of the correlation coefficient features an IOD-like pattern in the tropical Indian Ocean and El Niño-like pattern in the tropical Pacific Ocean. The correlation coefficients of the TCG EOF1 time series with DMI and Niño-3.4 indices are 0.45 and 0.35 , and significant at the $99 \%$ and $95 \%$ 
TABLE 1. List of the years at positive/negative phases of the TCG_EOF1 and IPT modes. The boldface type indicates the 13 positive years and 13 negative years that are described as "typical" in the text.

\begin{tabular}{|c|c|c|}
\hline & Positive years & Negative years \\
\hline TCG_EOF1 & $\begin{array}{l}\text { 1981, 1982, 1986, } 1989,1990, \mathbf{1 9 9 3}, \mathbf{1 9 9 4} \\
\text { 1997, 2002, 2003, 2004, 2006, 2009, } 2011, \\
\text { 2012, 2013, 2014, and } 2015\end{array}$ & $\begin{array}{l}\text { 1983, 1984, 1985, } 1987, \mathbf{1 9 8 8}, 1991, \mathbf{1 9 9 2} \\
\text { 1995, 1996, 2000, 2001, 2005, 2007, } \\
\text { 2008, and } 2010\end{array}$ \\
\hline IPT & $\begin{array}{l}\text { 1982, 1986, } 1987,1991,1993,1994,1997 \\
\text { 2002, 2003, 2004, 2006, 2009, 2012, } \\
\text { 2014, and } 2015\end{array}$ & $\begin{array}{l}1981, \mathbf{1 9 8 3}, \mathbf{1 9 8 4}, \mathbf{1 9 8 5}, \mathbf{1 9 8 8}, 1989,1990 \\
\mathbf{1 9 9 2}, \mathbf{1 9 9 5}, \mathbf{1 9 9 6}, \mathbf{2 0 0 0}, \mathbf{2 0 0 1}, \mathbf{2 0 0 5}, \mathbf{2 0 0 7} \\
\mathbf{2 0 0 8}, \mathbf{2 0 1 0}, 2011 \text {, and } 2013\end{array}$ \\
\hline
\end{tabular}

confidence levels, respectively. To note that, numerous works have revealed that intimate connections exist between the IOD and ENSO (e.g., Webster et al. 1999; Li et al. 2003; Xie et al. 2009). The correlation coefficient of DMI and Niño-3.4 is 0.63 , which is very high and significant at the $99 \%$ confidence level. After removing the Niño-3.4-regressed simultaneous signals, the correlation coefficient of the TCG EOF1 and DMI is decreased to 0.29 , but also significant at the $90 \%$ confidence level. These imply that the TCG EOF1 mode may relate to both ENSO and the IOD. However, ENSO and the IOD are closely linked, and it is hard to separate their individual effects completely, especially on an interannual time scale. Moreover, only focusing on a single basin mode of the IOD/ENSO also may not accurately reflect the individual effects. Thus, it is necessary to take the SSTAs of the tropical Indo-Pacific Ocean as a whole to investigate their combined influences on the TCG in the Indian Ocean.

Note that the signals in the eastern tropical Pacific Ocean are very strong while the SSTAs in the Indian Ocean are relatively weak (Ju et al. 2004; Xie et al. 2009). But the west-east zonal gradient of SSTAs in the Indian Ocean may also be very important to TCG. To investigate the combined impacts of the SSTAs in the tropical Indo-Pacific Ocean, we chose the western tropical Indian Ocean, Maritime Continent region, and the equatorial central-eastern Pacific Ocean, shown as three boxes with significant correlation coefficients in Fig. 4a, as the key regions to define an Indo-Pacific tripole (IPT) index for describing the tripole pattern of SSTAs in the tropical Indo-Pacific Ocean. The detailed formula of the IPT index is as follows:

$$
\mathrm{IPT}=\mathrm{SST}_{1}-\mathrm{SST}_{2}+\mathrm{SST}_{3}
$$

where $\mathrm{SST}_{1}, \mathrm{SST}_{2}$, and $\mathrm{SST}_{3}$ are the averaged SON SSTAs of the western tropical Indian Ocean $\left(10^{\circ} \mathrm{S}-10^{\circ} \mathrm{N}, 50^{\circ}-\right.$ $\left.70^{\circ} \mathrm{E}\right)$, the Maritime Continent region $\left(10^{\circ} \mathrm{S}-0^{\circ}, 90^{\circ}-\right.$ $140^{\circ} \mathrm{E}$ ), and the central-eastern equatorial Pacific Ocean $\left(5^{\circ} \mathrm{S}-5^{\circ} \mathrm{N}, 170^{\circ}-90^{\circ} \mathrm{W}\right)$, respectively. Previous studies have indicated that the tropical Indian and Pacific Oceans are closely connected through the Walker circulation and Indonesian Throughflow (Xie et al. 2009; Chen 2011; Lian et al. 2014; Huang et al. 2016; Li et al. 2018). Alongside the
Walker circulation anomalies over the tropical Indo-Pacific Ocean, opposite west-east gradients of sea surface temperature appear in the tropical Indian and Pacific Oceans, and the interbasin scale SSTAs of the tropical Indo-Pacific Ocean present as an obvious IPT pattern (Ju et al. 2004; Chen and Cane 2008; Chen 2011; Lian et al. 2014). EOF analysis of the averaged SON SSTAs in the tropical IndoPacific Ocean $\left(20^{\circ} \mathrm{S}-20^{\circ} \mathrm{N}, 40^{\circ} \mathrm{E}-90^{\circ} \mathrm{W}\right)$ during $1981-2015$ shows that the dominant EOF1 mode is a similar tripole pattern and can explains approximately $63 \%$ of the total SSTA variances (Fig. 4b). This EOF1 mode presents as an IOD-like pattern in the tropical Indian Ocean and an El Niño-like pattern in the tropical Pacific Ocean, which is consistent with the results in previous studies ( $\mathrm{Ju}$ et al. 2004; Chen 2011; Liu et al. 2019). The time series of the tropical Indo-Pacific SSTA EOF1 mode relates highly to the IPT index (Fig. 4c), and the correlation coefficient is 0.97. This indicates that the IPT pattern is a distinct combined mode of SSTAs in the tropical Indian and Pacific Oceans. Previous studies have revealed that the IPT mode can reflect the covariation/coexistence of the SSTAs of ENSO in the tropical Pacific Ocean and the IOD in the tropical Indian Ocean (Lian et al. 2014; Liu et al. 2019). By investigating the tropical Indo-Pacific Ocean SSTA modes on the TCG variation over the western North Pacific, Liu et al. (2019) found that the combined IPT mode can explain larger TCG variation than the individual SSTA modes in the tropical Indian and Pacific Oceans. This confirms our motivation to investigate the combined impacts of the IPT mode on the TCG in the Indian Ocean.

The TCG EOF1 mode is closely related to the IPT with a correlation coefficient of 0.45 and is significant at the $99 \%$ confidence level. Further analysis showed that 20 of a total of 35 years are at a TCG EOF1 positive phase, of which $65 \%$ of the years are in co-occurrence with IPT positive years (13 years); meanwhile, 15 years are at a TCG EOF1 negative phase, $87 \%$ of which are in cooccurrence with IPT negative phases (Table 1). To further validate the relationships between the Indian Ocean TCG EOF1 mode and the IPT pattern in the tropical IndoPacific Ocean, we chose the IPT positive (negative) phase years that are in co-occurrence with TCG EOF1 positive (negative) phase years as the typical IPT positive 
(a)

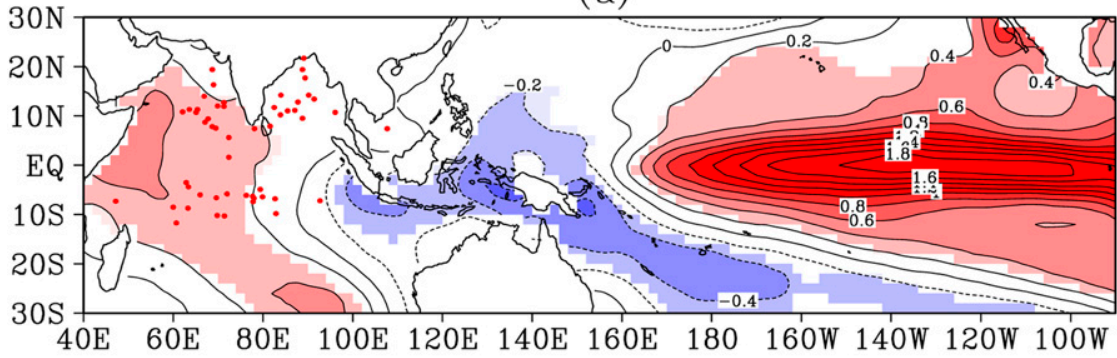

(b)
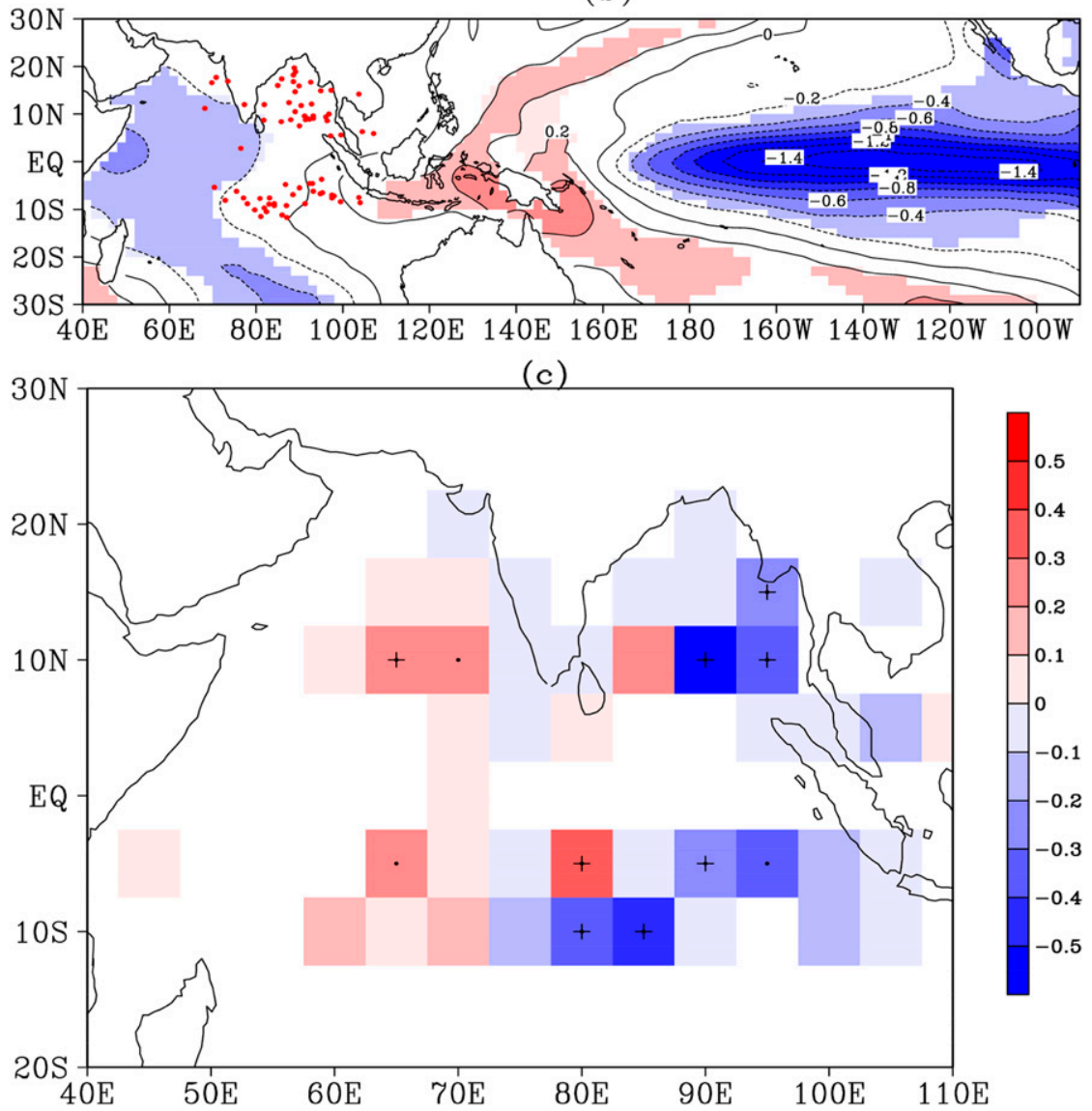

FIG. 5. Composite of the SON averaged SSTAs (contours; ${ }^{\circ} \mathrm{C}$ ) in the (a) typical positive IPT years and (b) typical negative IPT years. (c) The differences of TCG number between the typical positive and negative IPT years (shaded). The shaded parts in (a) and (b) indicate that the composited SSTAs pass the significance $t$ test at the $95 \%$ confidence level. The red dots in (a) and (b) indicate TCG locations. A black plus sign or dot in (c) indicates that the differences of TCG number pass the significance test at the $95 \%$ or $90 \%$ confidence level, respectively.

(negative) years. The 13 typical IPT positive years and 13 typical IPT negative years are presented in Table 1.

In typical IPT positive years, the SSTAs feature a tripole pattern in the tropical Indo-Pacific Ocean, with significant positive anomalies in the western tropical Indian Ocean and the central-eastern equatorial Pacific Ocean, but negative anomalies in the southeastern tropical Indian Ocean and western tropical Pacific Ocean (Fig. 5a).
Correspondingly, most TCs are generated in the west part of the Indian Ocean. Especially in the southern Indian Ocean, approximately $95 \%$ (18 out of a total of 19) of TCG is located west of $85^{\circ} \mathrm{E}$. However, in typical IPT negative years, the composite SSTAs also present as a tripole pattern in the tropical Indo-Pacific Ocean, but almost opposite to that in IPT positive years (Fig. 5b). TCs mainly are generated in the east part of the Indian Ocean. 

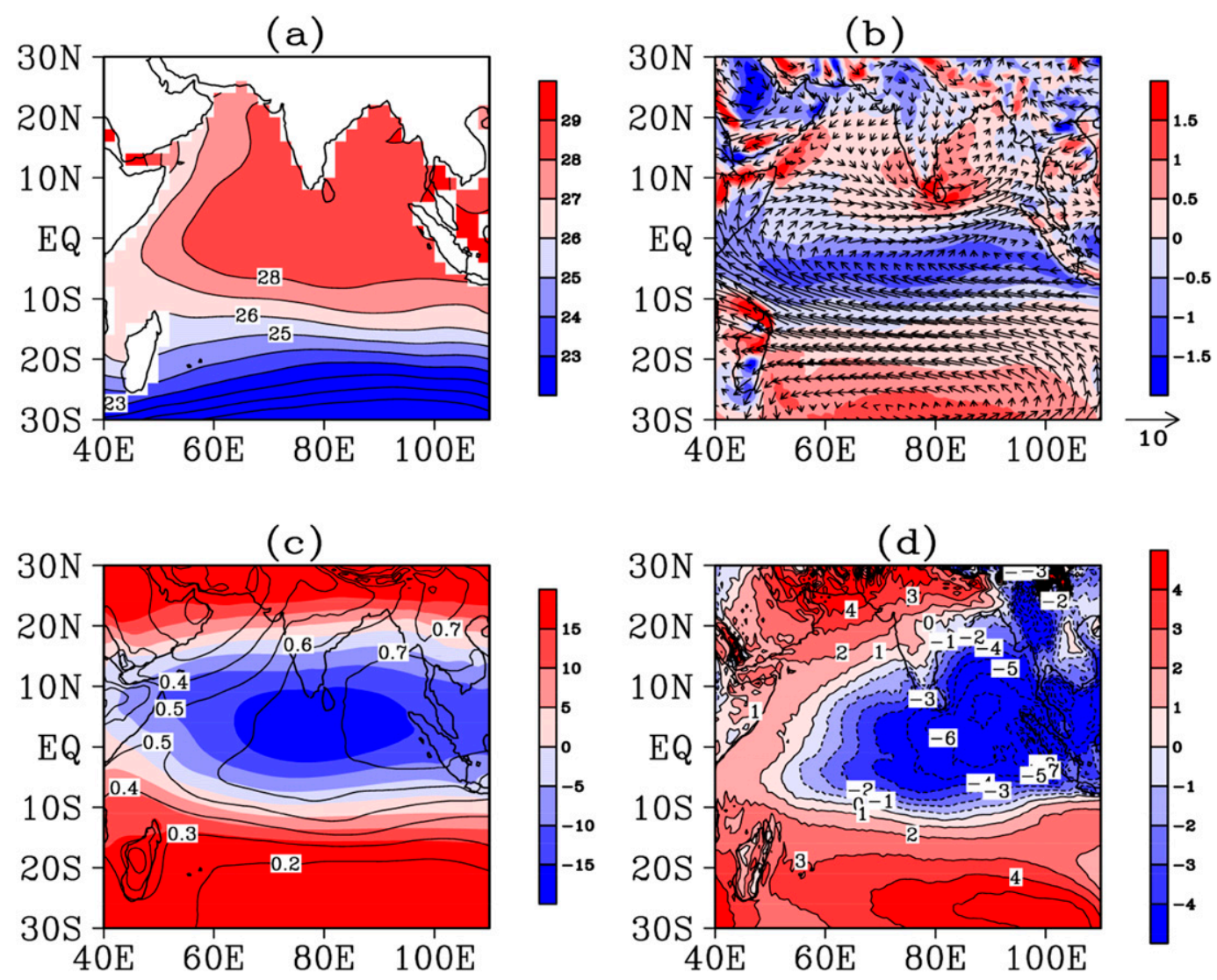

FIG. 6. The SON averaged (a) sea surface temperature $\left({ }^{\circ} \mathrm{C}\right.$ ), (b) $850-\mathrm{hPa}$ wind (vectors; $\mathrm{m} \mathrm{s}^{-1}$ ) and vorticity (shaded; $10^{-5} \mathrm{~s}^{-1}$ ), (c) vertical zonal wind shear between 200 and $850 \mathrm{hPa}$ (shaded; $\mathrm{m} \mathrm{s}^{-1}$ ) and 700-hPa specific humidity (contours; $10^{-2} \mathrm{~kg} \mathrm{~kg}^{-1}$ ), and (d) 500-hPa omega $\left(10^{-2} \mathrm{~Pa} \mathrm{~s}^{-1}\right)$ during 1981-2015.

In this composite, $82 \%$ ( 28 of a total of 34 ) of the north Indian Ocean TCG is in the BOB, and all TCs are formed east of $70^{\circ} \mathrm{E}$ in the south Indian Ocean. The differences of TCG between the typical positive and negative IPT years show that significant negative TCG anomalies appear in the southeastern Indian Ocean and BOB, while positive TCG anomalies appear in the southwestern Indian Ocean and AS (Fig. 5c). The above-mentioned correlation and composite analysis indicate that the zonal dipole pattern of TCG in the Indian Ocean is significantly related to the tropical Indo-Pacific tripole SSTA pattern.

We also carried out an SVD analysis of the Indian Ocean TCG frequency and tropical Indo-Pacific Ocean SSTAs and obtained an analogous coupled mode (figure not shown). In the SVD coupled mode, the SST field presents a distinct tripole variation pattern in the Indo-Pacific Ocean, and its correlation coefficient with the IPT is 0.9 , which is significant at the $99 \%$ confidence level; meanwhile, the Indian Ocean TCG field shows a zonal dipole pattern with high positive loadings centered in the $\mathrm{BOB}$ and southeastern Indian Ocean, and its correlation with the TCG EOF1 mode is 0.79 , which is also significant at the $99 \%$ confidence level.
The coupled mode is the first mode of the SVD analysis and occupies $72 \%$ of the coupled variance contributions, which can explain $\sim 62 \%$ of SSTAs of the tropical Indo-Pacific Ocean and $\sim 9 \%$ of TCG variations in the Indian Ocean. The SVD coupled mode reflects the relationship between the TCG EOF1 mode and IPT. According to the North's significance test, this SVD coupled mode is a clear and independent mode. These confirm that the zonal dipole TCG mode in the Indian Ocean is closely related to the IPT pattern of SSTAs in the tropical Indo-Pacific Ocean with certainty. More (fewer) TCs formed in the west (east) part of both the northern and southern Indian Ocean at IPT positive phases; the opposite is true at IPT negative phases.

\section{Modulation of Indian Ocean TCG environments by the tropical Indo-Pacific SSTAs}

\section{a. Climatic environments of the Indian Ocean in SON}

In SON, the warm sea surface temperature encompassed by the $26^{\circ} \mathrm{C}$ isothermal lines can be found north of $15^{\circ} \mathrm{S}$ in the southern Indian Ocean, the BOB, and the AS in the northern Indian Ocean (Fig. 6a). 
(a)

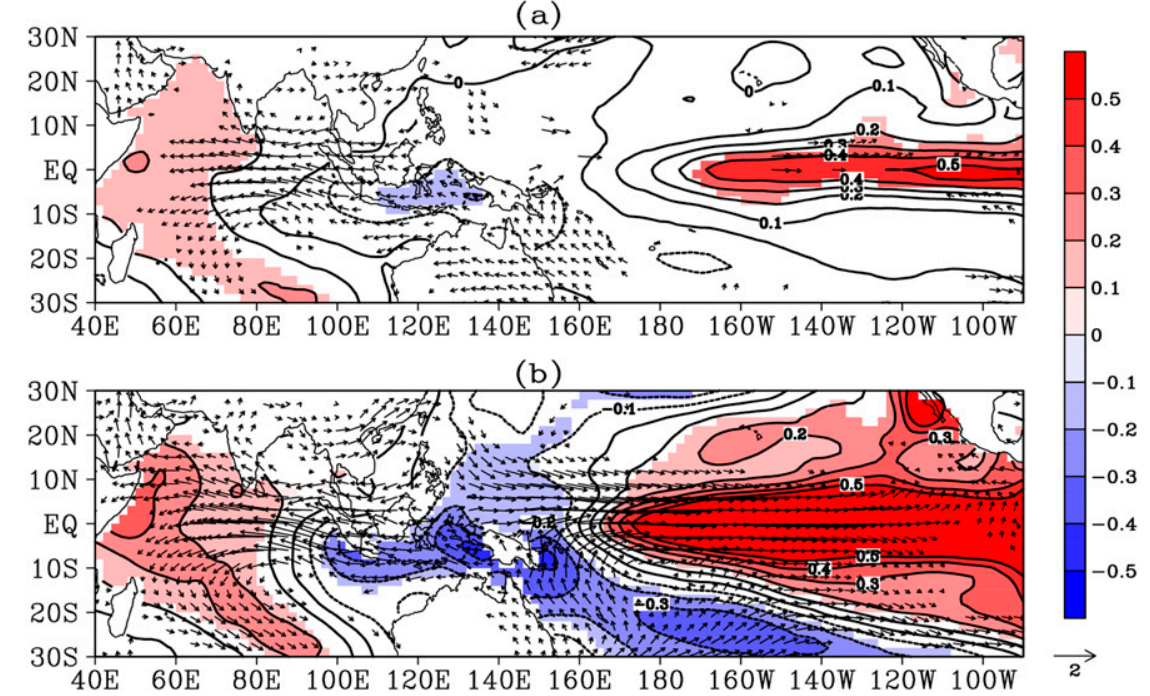

FIG. 7. The SON SSTAs (contour; ${ }^{\circ} \mathrm{C}$ ) and $850-\mathrm{hPa}$ wind (vector; $\mathrm{m} \mathrm{s}^{-1}$ ) regressed against (a) the TCG EOF1 time series and (b) IPT during 1981-2015. The anomalies are computed by removing the climatological SON seasonal means. The regressed SSTAs that pass the significance test at the $95 \%$ confidence level are also shown as shaded $\left({ }^{\circ} \mathrm{C}\right)$. The vectors only show the regressed wind anomalies that are statistically significant at the $95 \%$ confidence level.

Accompanying the easterly (westerly) wind in the south (north) of the equatorial Indian Ocean at $850 \mathrm{hPa}$, a pair of cyclonic wind curls appear around $5^{\circ}-15^{\circ}$ in the southern and northern regions of the tropical Indian Ocean. Strong cyclonic vorticities present in the tropical southern Indian Ocean, western AS, and BOB regions (Fig. 6b). The relative humidity shows a similar distribution pattern to the sea surface temperature field, with high values east of $60^{\circ} \mathrm{E}$ of the tropical Indian Ocean (Fig. 6c). The regions of weak vertical wind shear are located within a zonal strip $5^{\circ}-15^{\circ}$ on both sides of the Indian Ocean (Fig. 6c). Strong ascending motions mainly appear east of $60^{\circ} \mathrm{E}$ in the southern Indian Ocean and $\mathrm{BOB}$ regions (Fig. 6d).

\section{b. Favorable conditions for the zonal dipole pattern of TCG in the Indian Ocean}

To investigate the favorable conditions for the zonal dipole pattern of TCG in the Indian Ocean, we used the time series of TCG EOF1 mode to regress the oceanic and atmospheric environments. As shown in Fig. 7a, the regressed SSTAs show a distinct tripole pattern. Significant positive values appear in the western tropical Indian Ocean and central-eastern equatorial Pacific Ocean, while relatively weaker negative values appear in the southeastern tropical Indian Ocean and western tropical Pacific Ocean. The regressed SSTAs feature a negative zonal gradient of SSTAs in the tropical Indian Ocean. Note that the climatology of the sea surface temperature presents as higher values in the eastern tropical Indian Ocean and lower values in the western tropical Indian Ocean (Fig. 6a). The distribution of the SSTAs in Fig. 7a can decrease the climatic zonal sea surface temperature gradient in the tropical Indian Ocean; thus, significant anomalous easterly flow appears in the equatorial Indian Ocean (Fig. 7a). A pair of anticyclonic wind curl anomalies can be found in the north and south of the tropical Indian Ocean (Figs. 7a and 8a), and significant anticyclonic vorticity anomalies present in the southeastern tropical Indian Ocean and BOB regions (Fig. 8a). The regressed relative humidity field at $700 \mathrm{hPa}$ shows that significant positive anomalies occur in the western part of the Indian Ocean, but negative values appear in the southeastern Indian Ocean and northern BOB (Fig. 8c). The regressed 500-hPa omega also presents a zonal dipole pattern, and significant ascent anomalies in the western tropical Indian Ocean and descent anomalies in the BOB and southeastern Indian Ocean (Fig. 8e), while significant positive vertical wind shear anomalies mainly are located in the AS and eastern tropical Indian Ocean (Fig. 8g).

The GPI defined by Murakami and Wang (2010) was used to represent the co-contributions of the factors that are responsible for TCG in the Indian Ocean. As shown in Fig. 2b, the GPI distributions match well with the TCG locations, indicating that the GPI can well depict the TCG environments in the Indian Ocean climatologically. The GPI regressed by using the time series of the TCG EOF1 mode presents a zonal seesaw pattern in both the southern and northern Indian Ocean (Fig. 9a). 
(a)
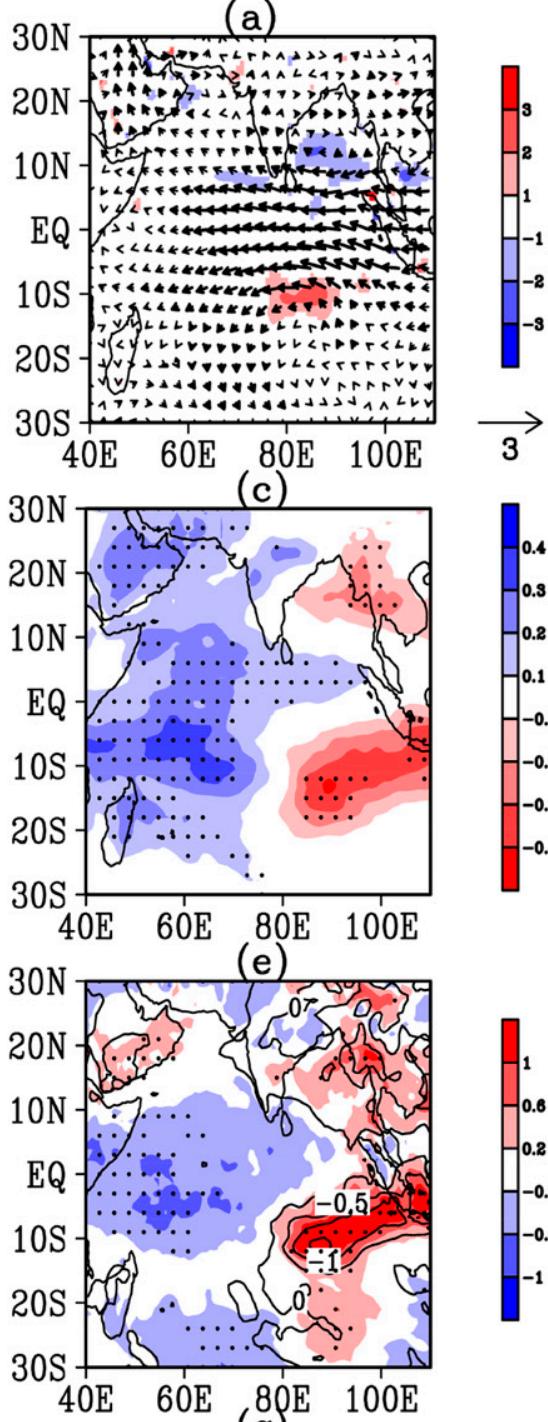

(g)

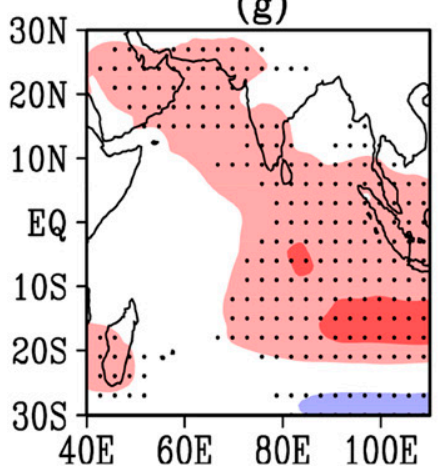

(b)

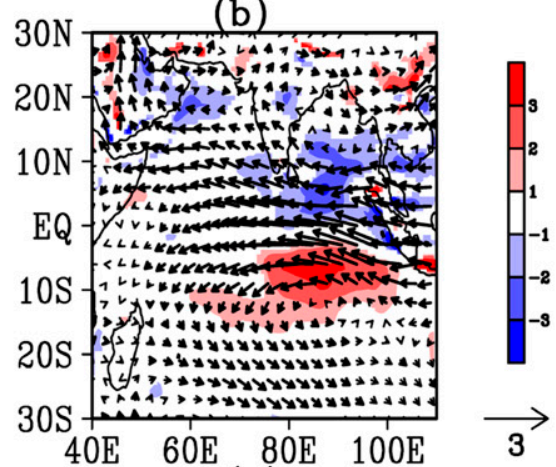

(d)

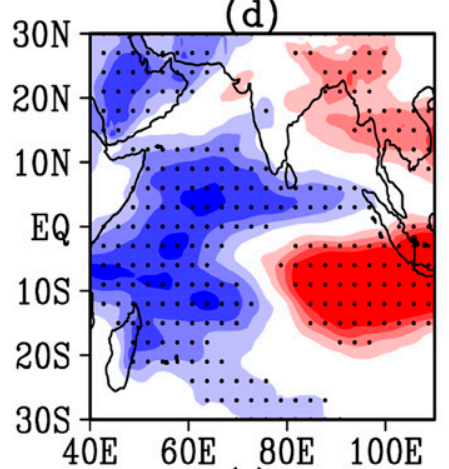

(f)

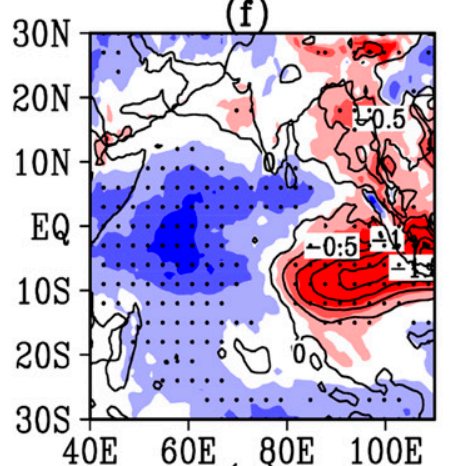

(h)

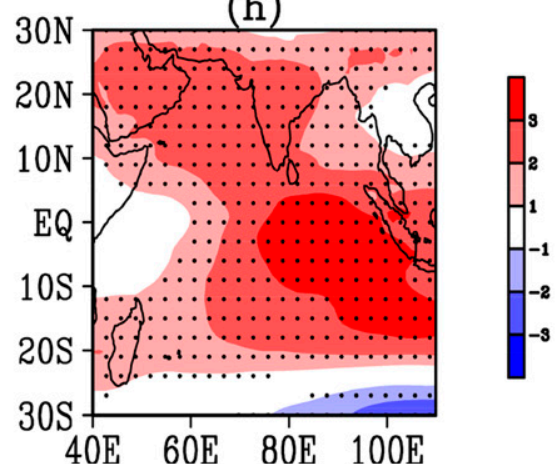

FIG. 8. As in Fig. 7, but for (a),(b) 850-hPa wind (vectors; $\mathrm{m} \mathrm{s}^{-1}$ ) and vorticity (shaded; $10^{-6} \mathrm{~s}^{-1}$ ); (c),(d) 700-hPa relative humidity (shaded; $10^{-2} \mathrm{~kg} \mathrm{~kg}^{-1}$ ); (e),(f) 500-hPa omega (shaded; $10^{-2} \mathrm{~Pa} \mathrm{~s}^{-1}$ ) and precipitation (only negative values are shown in contours; $\mathrm{mm} \mathrm{day}^{-1}$ ); and (g),(h) vertical zonal wind shear $\left(\mathrm{m} \mathrm{s}^{-1}\right)$, regressed against the (left) TCG EOF1 time series or (right) IPT. In (a) and (b), the regressed vorticity passing the significance test at the $95 \%$ confidence level is shaded, and thick black wind vectors indicate the regressed winds that are statistically significant at the $95 \%$ confidence level. The black dots in (c) and (d) denote the regressed relative humidity passing the significance test at the $95 \%$ confidence level. The black dots in (e) and (f) denote the regressed omega passing the significance test at the $95 \%$ confidence level. The black dots in (g) and (h) denote the regressed wind shear passing the significance test at the $95 \%$ confidence level. 
(a)

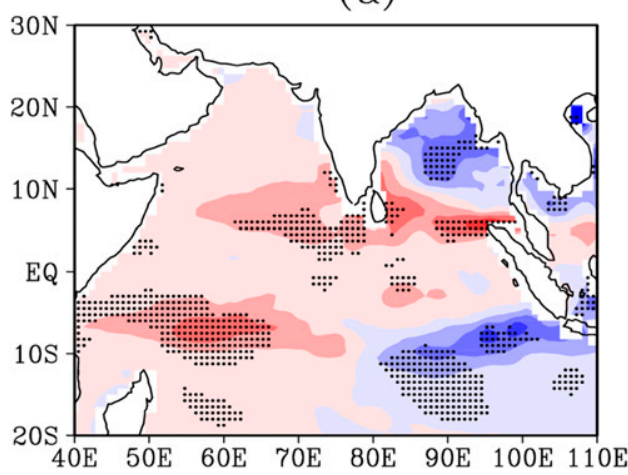

(b)

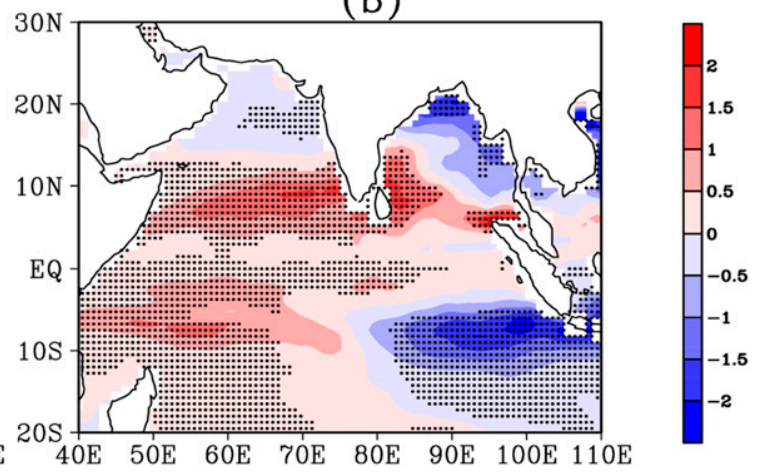

FIG. 9. As in Fig. 7, but for the GPI. Black dots denote the regressed GPI passing the significance test at the 95\% confidence level.

Significant positive GPI anomalies appear in the southwestern tropical Indian Ocean and AS, but negative values present in the southeastern tropical Indian Ocean and northern $\mathrm{BOB}$, indicating that the conditions favorable for TCG also present as a zonal dipole pattern.

Following Li et al. (2013), we applied the GPI quantitative method to assess the relative contribution of each large-scale factor on TCG. The GPI terms are averaged in four regions, with the AS region defined as $60^{\circ}-80^{\circ} \mathrm{E}$ and $5^{\circ}-20^{\circ} \mathrm{N}$, the BOB region defined as $90^{\circ}-$ $100^{\circ} \mathrm{E}$ and $5^{\circ}-20^{\circ} \mathrm{N}$, the southwestern Indian Ocean (SWIO) region defined as $60^{\circ}-80^{\circ} \mathrm{E}$ and $15^{\circ}-5^{\circ} \mathrm{S}$, and the southeastern Indian Ocean (SEIO) region defined as $80^{\circ}-100^{\circ} \mathrm{E}$ and $15^{\circ}-5^{\circ} \mathrm{S}$.

As shown in Fig. 10a, the relative contributions of the vorticity term are negative in all four regions, indicating that the low-level anticyclonic wind curls (Fig. 8a) are unfavorable for TCG in both the west and east parts of the tropical Indian Ocean. Especially in the BOB, the vorticity term exerts the largest negative contribution to GPI. Both the humidity and vertical motion terms show positive contributions in the AS and southwestern Indian Ocean, but negative contributions in the BOB and southeastern Indian Ocean. The moisture budget analysis by using the moisture tendency equation shows that the increase of special humidity at $700 \mathrm{hPa}$ in the AS and southwestern Indian Ocean is primarily attributed to the vertical motion transportation term, while the apparent moisture sink has a negative contribution (Fig. 11a). However, in the east part of the tropical Indian Ocean, the tendencies of special humidity anomaly are negative, primarily because of negative contributions of the vertical motion transportation term in the BOB and southeastern Indian Ocean (Fig. 11a). Thus, the humidity anomaly tendency at $700 \mathrm{hPa}$ is closely related to the vertical motion transportation term. Alongside significant anomalous ascending (descending) motion in the AS and southwestern Indian Ocean (BOB and southeastern Indian Ocean) (Fig. 8e), more (less) water vapor is transported upward to the lower-middle troposphere, which is favorable (unfavorable) for deepening the moist layer and causing more (less) TCG in the western (eastern) part of the tropical Indian Ocean. It appears that the west-east seesaw distributions of the humidity and vertical motion terms are important to the zonal dipole pattern of TCG in the Indian Ocean. The co-contributions of the humidity and vertical motion terms to the total GPI in all of the four regions are more than $50 \%$, and show positive (negative) contributions in the west (east) part of the tropical Indian Ocean (Fig. 10a). The contributions of the maximum potential intensity (PI) terms are relatively weak in the Indian Ocean. The vertical wind shear term presents positive contributions in all the four regions, especially with strong positive contributions in $\mathrm{BOB}$ and $\mathrm{AS}$ regions. This is because the westerly wind shear anomalies (Fig. 8g) can reduce the climatic easterly wind shear (Fig. 6c); thus, it is favorable for TCG in the whole Indian Ocean basin.

It appears that the west-east seesaw distributions of the lower-middle-level humidity and vertical motion anomalies are important to the zonal dipole pattern of TCG in the Indian Ocean. In the western part of the tropical Indian Ocean, the positive contributions of the humidity and vertical motion terms combined with the vertical wind shear term can overcome the negative effects of the low-level vorticity term, which is favorable for more TCG, while the combined negative contributions of the humidity, vertical motion, and vorticity terms result in less TCG in the eastern part of the tropical Indian Ocean.

\section{c. Modulation of Indian Ocean TCG environments by the tropical Indo-Pacific SSTAs}

To investigate the modulation of TCG environments by the tropical Indo-Pacific SSTAs, we also use the IPT 
(a) TCG EOF1

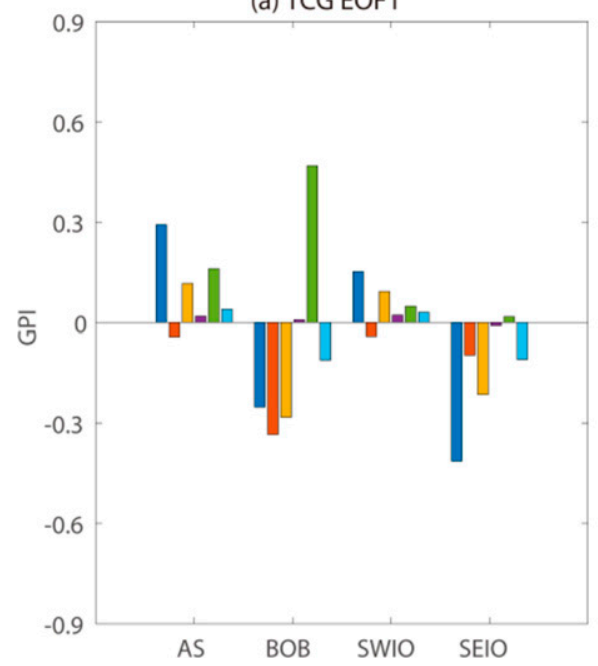

(b) IPT

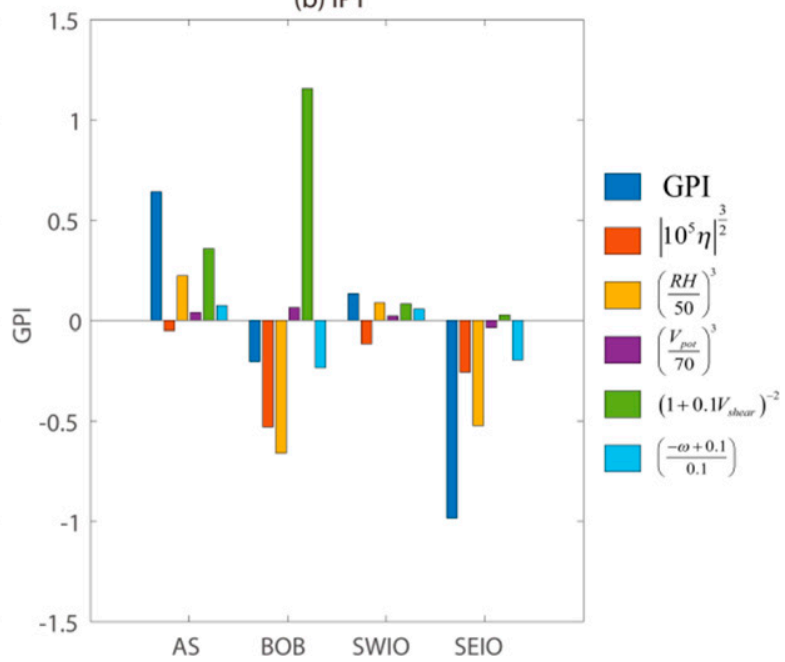

FIG. 10. The contributions of each of the GPI terms that are regressed against the (a) TCG EOF1 time series and (b) IPT. The AS region is defined as $60^{\circ}-80^{\circ} \mathrm{E}$ and $5^{\circ}-20^{\circ} \mathrm{N}$, the BOB region is defined as $90^{\circ}-100^{\circ} \mathrm{E}$ and $5^{\circ}-20^{\circ} \mathrm{N}$, the SWIO region is defined as $60^{\circ}-80^{\circ} \mathrm{E}$ and $15^{\circ}-5^{\circ} \mathrm{S}$, and the SEIO region is defined as $80^{\circ}-100^{\circ} \mathrm{E}$ and $15^{\circ}-5^{\circ} \mathrm{S}$.

index to regress the large-scale factors of TCG environments. Accompanying the IPT index variations, the SSTAs in the tropical Indo-Pacific Ocean features significant positive anomalies that appear in the western tropical Indian Ocean and central-eastern equatorial Pacific Ocean, but negative values appear in the Maritime Continent regions (Fig. 7b). The tripole SSTAs pattern can leads to negative (positive) zonal gradients of sea surface temperature and significant lower-level easterly (westerly) wind anomalies in the tropical Indian (Pacific) Ocean (Fig. 7b). The low-level easterly wind anomalies in the tropical Indian Ocean and the westerly wind anomalies in the tropical Pacific Ocean further cause obvious lowerlevel divergence and force significant descending motion anomalies in the Maritime Continent regions (Figs. 7b and 8f). Previous works have indicated that the Walker circulations overlying the tropical Indian and Pacific Oceans operate like two coupled gears, and are closely connected by the common vertical motion branch over the Maritime Continent regions (Wu and Meng 1998; Meng and Wu 2000). Therefore, the anomalous descending motion over the Maritime Continent regions also can trigger the Walker circulation anomalies over both the tropical Indian and Pacific Oceans (Fig. 12b). (a) TCG EOF1

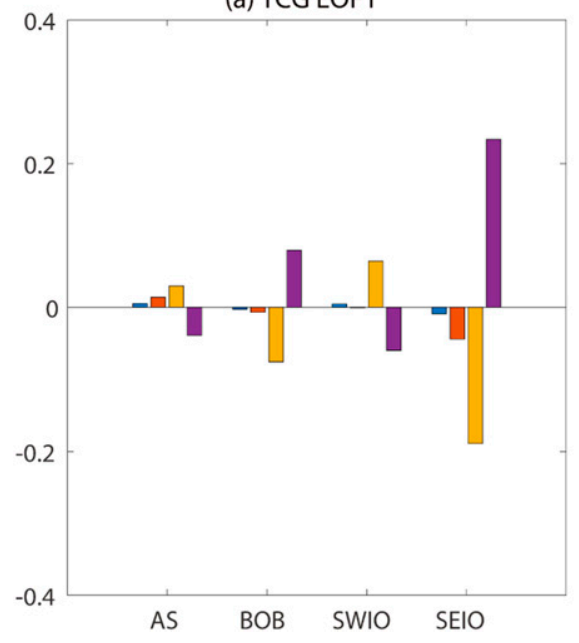

(b) IPT

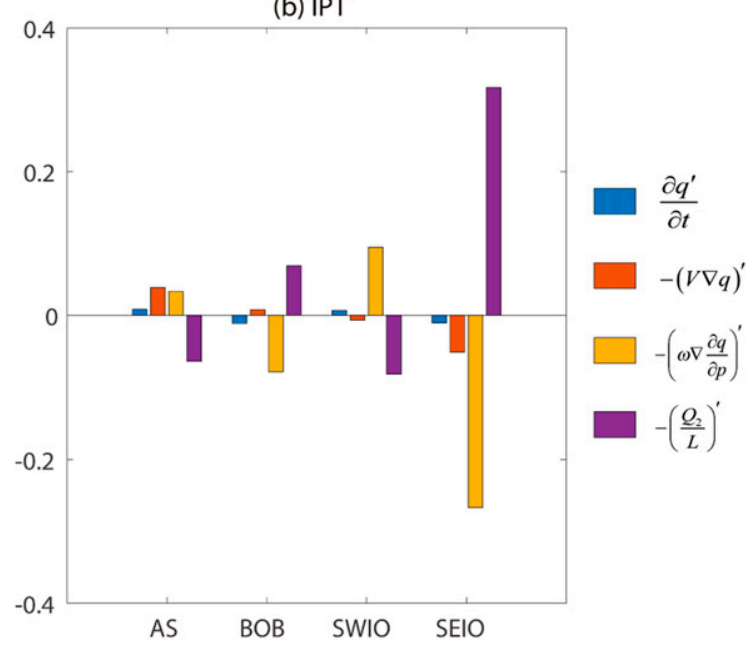

FIG. 11. As in Fig. 10, but for the contributions of each term of the moisture tendency equation at $700 \mathrm{hPa}$ $\left(10^{-8} \mathrm{~kg} \mathrm{~kg}^{-1} \mathrm{~s}^{-1}\right)$. 
(a)

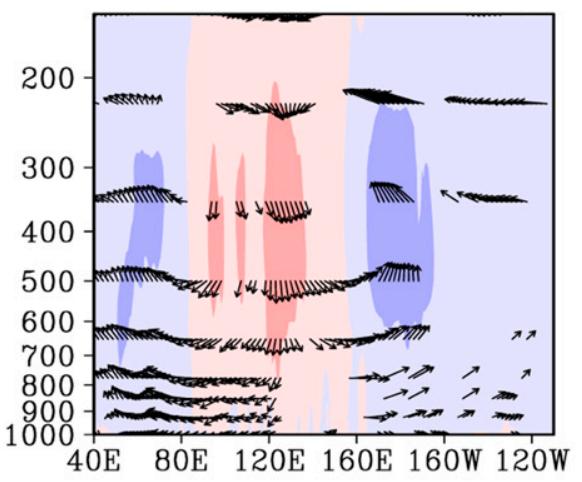

2

(c)

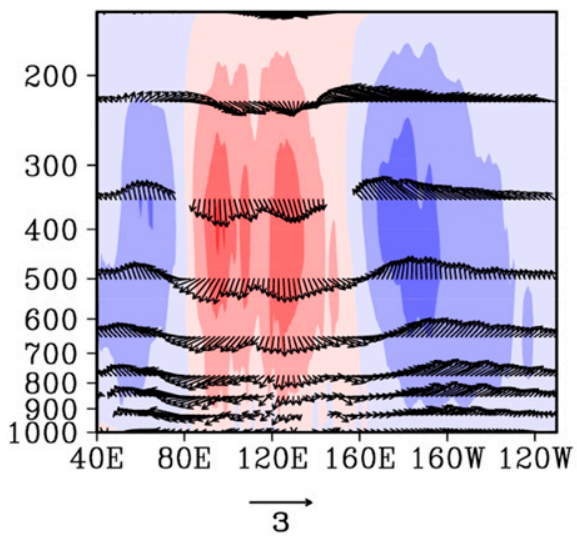

(b)

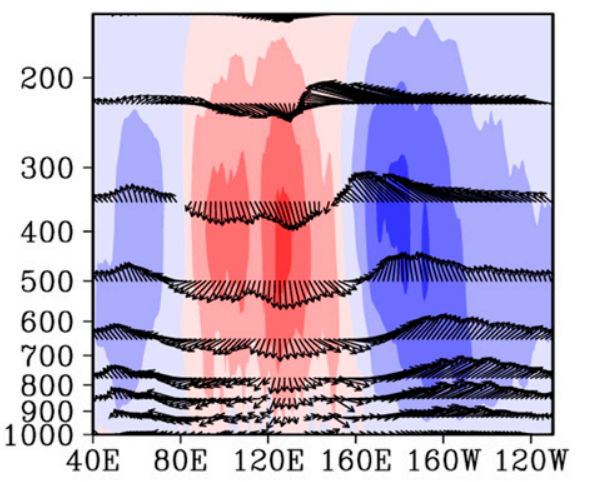

3

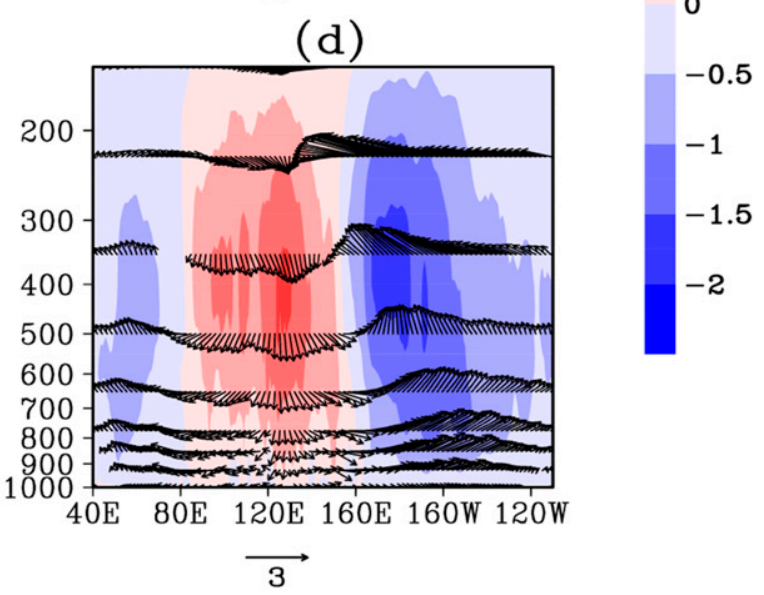

FIG. 12. The vertical sections of velocity averaged in $10^{\circ} \mathrm{S}-10^{\circ} \mathrm{N}$ regions, which are regressed against the (a) TCG EOF1 time series, (b) IPT, (c) DMI, and (d) Niño-3.4 index. Shading denotes the omega $\left(10^{-2} \mathrm{~Pa} \mathrm{~s}^{-1}\right)$. Vectors denote that the regressed velocity passes the significance test at the $95 \%$ confidence level.

Associated with the SSTAs of IPT, an obvious local Walker circulation anomaly can be found over the tropical Indian Ocean. Significant ascending (descending) motion anomalies appear over the western (eastern) tropical Indian Ocean, easterly wind anomalies appear in the lower troposphere, and westerly wind anomalies appear in the upper troposphere over the tropical Indian Ocean (Fig. 12b). The local Walker circulation anomaly can significantly modify the TCG environments in the entire tropical Indian Ocean basin. The possible physical processes and interpretations are analyzed below.

First, the anomaly of the vertical branch of the local Walker circulation can influence the upward moisture transportation. The moisture budget analysis shows that the vertical motion transportation term is primarily attributed to the negative humidity anomalies tendency at $700 \mathrm{hPa}$ in the eastern part of the tropical Indian Ocean. In the southwestern Indian Ocean, the vertical motion transportation term exerts the largest contribution to the positive tendency of the humidity anomalies. And in the AS region, the combined positive contributions of the vertical motion transportation term and horizontal moisture advection term can overcome the negative effect of the apparent moisture sink and result in a positive humidity anomalies tendency (Fig. 11b). Thus, it appears that the humidity anomaly tendency distribution pattern of positive in the west and negative in the east in the tropical Indian Ocean is closely related to the vertical motion transportation term. The anomalous ascending (descending) vertical motion can transport more (less) water vapor to the lower-middle troposphere and is favorable (unfavorable) for TCG in the western (eastern) part of the tropical Indian Ocean. GPI contribution analysis also shows that the changes of the humidity term contribute greatly to the TCG variation, especially for acting as the largest negative term contribute to the TCG reductions in the BOB and southeastern tropical Indian Ocean (Fig. 10b).

Second, the descending motion anomalies in the eastern part of the tropical Indian Ocean are unfavorable for 
convection, and lead to negative precipitation anomalies in the $\mathrm{BOB}$ and southeastern tropical Indian Ocean (Fig. 8f). As a Rossby wave response to the suppressed precipitation and related atmospheric heat sink, a pair of significant anticyclonic wind curl anomalies can be found in the lower atmosphere of the tropical Indian Ocean (Fig. 8b). These anticyclonic wind anomalies can significantly reduce the lower troposphere cyclonic vorticity and are unfavorable for TCG in the eastern part of the tropical Indian Ocean (Figs. 8b and 9b). The vorticity term is the second largest negative term contributing to the TCG reductions in both the BOB and southeastern tropical Indian Ocean (Fig. 10b).

Third, the Walker circulation anomalies can also modify the zonal wind shear between the upper and lower levels. The induced westerly wind anomalies in the upper level and easterly wind anomalies in the lower level can result in significant westerly wind shear over the entire tropical Indian Ocean basin (Fig. 8h). It should be noted that the climatology of the vertical wind shear over the tropical Indian Ocean in SON is easterly wind shear (Fig. 6c). Thus, the westerly wind shear can reduce the climatic vertical wind shear and exert a positive contribution to the GPI variation over the whole tropical Indian Ocean (Fig. 10b). Quantitative GPI analysis shows that the vertical shear term is important to the total of GPI variance in the western part of the tropical Indian Ocean, which acts as the largest (second largest) positive contribution term in the AS (southwestern tropical Indian Ocean). Note also that in the BOB region, although the vertical shear term shows great positive contribution to the GPI variance, the combined negative effects of the vorticity, humidity, and vertical motion terms can overcome the positive contribution of the vertical shear term, and result in TC reduction. In contrast, the contribution of the vertical shear term to TCG is relatively small in the southeastern tropical Indian Ocean (Fig. 10b).

The Indian Ocean TCG is significantly affected by the combined tripole pattern of SSTAs in the tropical Indian and Pacific Oceans. The regressed Indo-Pacific Ocean SSTAs and the above atmospheric environments related to the IPT index exhibits very similar figures to those regressed by the TCG EOF1 mode (Figs. 7 and 8). The IPT pattern is related to the zonal dipole pattern of TCG in the Indian Ocean, by modifying the local Walker circulation and TCG environments. Associated with a positive phase of IPT, abnormal ascending (descending) motions are induced and favorable for more (less) water vapor transport to the lower-middle level in the western (eastern) tropical Indian Ocean; significant anticyclonic wind anomalies are evoked in the lower level in the eastern part of the tropical Indian Ocean, and weak easterly vertical wind shear appears over the tropical Indian Ocean. Thus, abnormally strong upward motion, abundant water vapor, and weak vertical wind shear are favorable for more TCG in the western part of the tropical Indian Ocean, while the combined negative contributions of the vertical motion, low-level vorticity, and humidity terms result in less TCG in the eastern part of the tropical Indian Ocean.

\section{d. Possible links of the IOD/ENSO with the IPT and Indian Ocean TCG zonal dipole pattern}

Numerous studies have revealed that intimate connections exist in the air-sea interactions between the tropical Indian and Pacific oceans (e.g., Wu and Meng 1998; Klein et al. 1999; Li et al. 2003; Meyers et al. 2007; Chen and Cane 2008; Xie et al. 2009). The dominant mode of the SSTAs in the tropical Indian and Pacific Oceans is characterized as an obvious interbasin IPT pattern (Ju et al. 2004; Chen 2011; Lian et al. 2014; Li et al. 2018; Liu et al. 2019), which features IOD-like SSTAs in the tropical Indian Ocean and El Niño-like SSTAs in the tropical Pacific Ocean (Fig. 4b). The correlation coefficients of the IPT with the DMI and Niño3.4 indices are 0.8 and 0.94 , respectively. Recently, the IPT mode is widely treated as an interbasin mode and combines the signals of both the IOD and ENSO (Lian et al. 2014; Li et al. 2018; Liu et al. 2019).

Further analysis indicated that both of the DMI and Niño-3.4 indices have significant correlations with the TCG EOF1 mode, with the correlation coefficients of 0.45 and 0.35 and are significant at the $99 \%$ and $95 \%$ confidence levels, respectively. The atmospheric circulation anomalies regressed by the DMI and Niño-3.4 indices also present similar configures as those regressed by the IPT and the TCG EOF1 mode (Fig. 12). Obvious Walker circulations anomalies appear overlying the tropical Indian and Pacific Oceans, which operate like two coupled gears and are closely connected by the common vertical motion branch over the Maritime Continent regions, consistent with the present studies (e.g., Wu and Meng 1998; Meng and Wu 2000; Ju et al. 2004; Lian et al. 2014). Through this kind of atmospheric bridge, ENSO signals over the Pacific Ocean and the IOD impacts over the Indian Ocean are closely connected, and may exert combined effects on the dipole pattern of TCG in the Indian Ocean through modifying the local Walker circulation anomalies.

To quantitatively depict the differences of TCG between the western and eastern parts of the tropical Indian Ocean, a TCG_Dipole index is defined as the difference of the averaged SON TCG number between the western $\left(40^{\circ}-80^{\circ} \mathrm{E}, 20^{\circ} \mathrm{S}-20^{\circ} \mathrm{N}\right)$ and eastern $\left(90^{\circ}-100^{\circ} \mathrm{E}\right.$, $\left.20^{\circ} \mathrm{S}-20^{\circ} \mathrm{N}\right)$ tropical Indian Ocean. The TCG_Dipole 
index is highly related to the time series of the TCG EOF1 mode, with the correlation coefficient of 0.62 . Thus, the TCG_Dipole index can quantitatively represent the variations of the zonal dipole pattern of TCG. To further determine the possible links between the IPT, ENSO, IOD, and Indian Ocean TCG dipole pattern, we established multiple linear regression equations of TCG_Dipole variation on the combined DMI and Niño-3.4 indices [Eq. (5)], and the SSTAs of three key regions which are used to compute the IPT index [Eq. (6)], respectively.

As shown in Eq. (5),

TCG_Dipole $=0.575 \times$ DMI $+0.565 \times$ Niño3.4,

TCG_Dipole significantly relates to both the DMI and the Niño-3.4 indices, with the correlation coefficients of 0.575 and 0.565 , respectively. The regressed TCG_ Dipole is significantly correlated with the raw dataset of TCG_Dipole; its correlation coefficient is 0.63 and significant at the $99 \%$ confidence level. The combined contributions of the DMI and Niño-3.4 indices to TCG Dipole variance are approximately $39 \%$, while the individual contributions of the DMI and Niño-3.4 indices are $33 \%$ and $32 \%$, respectively. These indicate that both the DMI and Niño-3.4 indices relate to the zonal dipole pattern of TCG in the Indian Ocean, but note that the IOD and ENSO are not independent, with a high correlation coefficient of 0.63 .

Equation (6) shows the multiple linear regression analysis of TCG_Dipole on the IPT index:

$$
\begin{aligned}
\text { TCG_Dipole }= & 0.586 \times \mathrm{SST}_{1}-0.482 \\
& \times \mathrm{SST}_{2}+0.550 \times \mathrm{SST}_{3} .
\end{aligned}
$$

By using the IPT index, the correlation coefficient between the raw TCG_Dipole and the regressed TCG Dipole is increased from 0.63 (with results from the combined IOD/ENSO regression model) to 0.69 (with results from the IPT regression model), and the contribution of the IPT index to the TCG_Dipole variance is improved to approximately $48 \%$. These imply that considering the interbasin IPT mode of the tropical Indo-Pacific Ocean as a whole and using the IPT index may be better for explaining the variances of the TCG zonal dipole pattern in the Indian Ocean. On the one hand, the Indian Ocean TCG dipole pattern is appears to accompany the coupled gear-like operating Walker circulation anomalies over both the tropical Indian and Pacific Oceans (Fig. 12a). And the IPT mode can represents the combined interbasin SSTAs of both the tropical Indian and Pacific Oceans, and has a better relationship with the TCG dipole pattern in the Indian
Ocean. On the other hand, the IOD and ENSO events are closely connected by complex atmospheric and oceanic processes (e.g., Li et al. 2003; Xie et al. 2009; Ha et al. 2017). It is hard to separate the individual effect of the IOD/ENSO on the TCG variances in the Indian Ocean. And it is also difficult to determine the linear combination of the IOD/ENSO effect, especially when the IOD and ENSO events have opposite effects on the TCG.

\section{Summary}

From a basinwide perspective, the dominant mode of the Indian Ocean TCG in SON shows an equatorially symmetric east-west zonal dipole pattern, indicating that the frequency of TCG covaries oppositely in the east and west parts of both the northern and southern Indian Ocean. This zonal dipole TCG pattern can explain approximately $13 \%$ of the SON TCG variance.

The Indian Ocean TCG zonal dipole pattern is significantly related to the IPT pattern of the tropical IndoPacific Ocean. The IPT, which is a combined interbasin mode and features a dipole pattern of SSTAs in the tropical Indian Ocean and El Niño-like SSTAs in the tropical Pacific Ocean, can influence the local Walker circulation and TCG environments over the tropical Indian Ocean. Associated with a positive IPT phase, abnormal ascending (descending) motions are induced and favorable for more (less) water vapor transport to the lower-middle level in the western (eastern) tropical Indian Ocean; significant anticyclonic vorticity anomalies are evoked in the lower level over the eastern tropical Indian Ocean, and weak easterly vertical wind shear appears over the tropical Indian Ocean. Thus, abnormally strong upward motion, abundant water vapor in lowermiddle level, and weak vertical wind shear are favorable for more TCG in the western tropical Indian Ocean, while the combined negative contributions of the vertical motion, lower-level vorticity, and humidity terms result in less TCG in the eastern tropical Indian Ocean.

The combined interbasin IPT mode shows stronger effect on the Indian Ocean zonal dipole pattern of TCG than the individual ENSO/IOD modes and can explain larger variances of the TCG dipole mode. The results of this study may provide a better understanding of the relationship between the Indo-Pacific Ocean SSTAs and the TCG over the Indian Ocean. Note, however, that the relative contribution of each large-scale factor to TCG appears to be different in the northern and southern Indian Ocean. For example, the vertical wind shear term makes the largest contribution to the TCG in the northern Indian Ocean but contributes a relatively small amount in the southern Indian Ocean. 
Detailed differences between the TCG variations in the northern and southern Indian Ocean, even in similar large-scale environments, also need to be further investigated in the future.

Acknowledgments. This work was supported by the National Natural Science Foundation of China (41875109, 41805059), the Natural Science Foundation of Yunnan Province (Grant 2018FB074), the Educational Foundation of Yunnan Province (Grant 2018JS014), and the Chinese Jiangsu Collaborative Innovation Center for Climate Change.

\section{REFERENCES}

Ash, K. D., and C. J. Matyas, 2012: The influences of ENSO and the subtropical Indian Ocean dipole on tropical cyclone trajectories in the southwestern Indian Ocean. Int. J. Climatol., 32, 4156, https://doi.org/10.1002/joc.2249.

Balaguru, K., L. R. Leung, J. Lu, and G. R. Foltz, 2016: A meridional dipole in premonsoon Bay of Bengal tropical cyclone activity induced by ENSO. J. Geophys. Res., 121, 6954-6968, https://doi.org/10.1002/2016JD024936.

Bister, M., and K. A. Emanuel, 1998: Dissipative heating and hurricane intensity. Meteor. Atmos. Phys., 65, 233-240, https:// doi.org/10.1007/BF01030791.

Chen, D., 2011: Indo-Pacific tripole: An intrinsic mode of tropical climate variability. Adv. Geosci., 24, 1-18, https://doi.org/ 10.1142/9789814355353_0001.

—_, and M. A. Cane, 2008: El Niño prediction and predictability. J. Comput. Phys., 227, 3625-3640, https://doi.org/10.1016/ j.jcp.2007.05.014.

Chu, J. H., C. R. Sampson, A. S. Levine, and E. Fukada, 2002: The Joint Typhoon Warning Center tropical cyclone best-tracks, 1945-2000. Naval Research Laboratory Tech. Rep. NRL/MR/ 7540-02-16, https://www.metoc.navy.mil/jtwc/products/besttracks/tc-bt-report.html.

Dee, D. P., and Coauthors, 2011: The ERA-Interim reanalysis: Configuration and performance of the data assimilation system. Quart. J. Roy. Meteor. Soc., 137, 553-597, https://doi.org/ 10.1002/qj.828.

Emanuel, K. A., 1995: Sensitivity of tropical cyclones to surface exchange coefficients and a revised steady-state model incorporating eye dynamics. J. Atmos. Sci., 52, 3969-3976, https:// doi.org/10.1175/1520-0469(1995)052<3969:SOTCTS >2.0.CO;2.

- , and D. S. Nolan, 2004: Tropical cyclone activity and the global climate system. 26th Conf. on Hurricanes and Tropical Meteorology, Miami, FL, Amer. Meteor. Soc., 10A.2, https:// ams.confex.com/ams/26HURR/techprogram/paper_75463.htm.

Felton, C. S., B. Subrahmanyam, and V. S. N. Murty, 2013: ENSOmodulated cyclogenesis over the Bay of Bengal. J. Climate, 26, 9806-9818, https://doi.org/10.1175/JCLI-D-13-00134.1.

Girishkumar, M. S., and M. Ravichandran, 2012: The influences of ENSO on tropical cyclone activity in the Bay of Bengal during October-December. J. Geophys. Res., 117, C02033, https:// doi.org/10.1029/2011JC007417.

— , V. P. T. Prakash, and M. Ravichandran, 2015: Influence of Pacific decadal oscillation on the relationship between ENSO and tropical cyclone activity in the Bay of Bengal during October-December. Climate Dyn., 44, 3469-3479, https:// doi.org/10.1007/s00382-014-2282-6.
Gray, W. M., 1968: Global view of the origin of tropical disturbances and storms. Mon. Wea. Rev., 96, 669-700, https://doi.org/ 10.1175/1520-0493(1968)096<0669:GVOTOO>2.0.CO;2.

_ 1979: Hurricanes: Their formation, structure and likely role in the tropical circulation. Meteorology over the Tropical Oceans, D. B. Shaw, Ed., Royal Meteorological Society, 155-218.

Ha, K.-J., J.-E. Chu, J.-Y. Lee, and K.-S. Yun, 2017: Interbasin coupling between the tropical Indian and Pacific Ocean on interannual timescale: Observation and CMIP5 reproduction. Climate Dyn., 48, 459-475, https://doi.org/10.1007/s00382-0163087-6.

Ho, C.-H., J.-H. Kim, J.-H. Jeong, H.-S. Kim, and D. Chen, 2006: Variation of tropical cyclone activity in the South Indian Ocean: El Niño-Southern Oscillation and Madden-Julian Oscillation effects. J. Geophys. Res., 111, D22101, https:// doi.org/10.1029/2006JD007289.

Hsu, P. C., and T. Li, 2012: Role of the boundary layer moisture asymmetry in causing the eastward propagation of the Madden-Julian oscillation. J. Climate, 25, 4914-4931, https:// doi.org/10.1175/JCLI-D-11-00310.1.

Huang, G., K. M. Hu, X. Qu, W. C. Tao, S. L. Yao, G. J. Zhao, and W. P. Jiang, 2016: A review about Indian Ocean basin mode and its impacts on East Asian summer climate. Chin. J. Atmos. Sci., 40, 121-130.

Ju, J.-H., L.-L. Chen, and C.-Y. Li, 2004: The preliminary research of Pacific-Indian Ocean sea surface temperature anomaly mode and the definition of its index. J. Trop. Meteor., 6, 617-624.

Klein, S. A., B. J. Soden, and N.-C. Lau, 1999: Remote sea surface temperature variations during ENSO: Evidence for a tropical atmospheric bridge. J. Climate, 12, 917-932, https://doi.org/ 10.1175/1520-0442(1999)012<0917:RSSTVD>2.0.CO;2.

Kuleshov, Y., L. Qi, R. Fawcett, and D. Jones, 2008: On tropical cyclone activity in the Southern Hemisphere: Trends and the ENSO connection. Geophys. Res. Lett., 35, L14S08, https:// doi.org/10.1029/2007GL032983.

Li, C. Y., L. I. Xin, Y. Hui, P. Jing, and L. I. Gang, 2018: Tropical Pacific-Indian Ocean associated mode and its climatic impacts. Chin. J. Atmos. Sci., 42, 505-523.

Li, T., B. Wang, C. P. Chang, and Y. Zhang, 2003: A theory for the Indian Ocean dipole-zonal mode. J. Atmos. Sci., 60, 21192135, https://doi.org/10.1175/1520-0469(2003)060<2119: ATFTIO $>2.0 . \mathrm{CO} ; 2$.

Li, Z., W. Yu, T. Li, V. S. N. Murty, and F. Tangang, 2013: Bimodal character of cyclone climatology in the Bay of Bengal modulated by monsoon seasonal cycle. J. Climate, 26, 1033-1046, https://doi.org/10.1175/JCLI-D-11-00627.1.

,,-- K. Li, B. Liu, and G. Wang, 2015: Modulation of interannual variability of tropical cyclone activity over Southeast Indian Ocean by negative IOD phase. Dyn. Atmos. Oceans, $\mathbf{7 2}$, 62-69, https://doi.org/10.1016/j.dynatmoce.2015.10.006.

_ T. Li, W. Yu, K. Li, and Y. Liu, 2016: What controls the interannual variation of tropical cyclone genesis frequency over Bay of Bengal in the post-monsoon peak season? Atmos. Sci. Lett., 17, 148-154, https://doi.org/10.1002/asl.636.

Lian, T., D. Chen, Y. Tang, and B. Jin, 2014: A theoretical investigation of the tropical Indo-Pacific tripole mode. Sci. China Earth Sci., 57, 174-188, https://doi.org/10.1007/s11430-013-4762-7.

Liu, K. S., and J. C. L. Chan, 2012: Interannual variation of Southern Hemisphere tropical cyclone activity and seasonal forecast of tropical cyclone number in the Australian region. Int. J. Climatol., 32, 190-202, https://doi.org/10.1002/joc.2259.

Liu, Y., P. Huang, and G. Chen, 2019: Impacts of the combined modes of the tropical Indo-Pacific sea surface temperature 
anomalies on the tropical cyclone genesis over the western North Pacific. Int. J. Climatol., 39, 2108-2119, https://doi.org/ 10.1002/joc.5938.

Mahala, B. K., B. K. Nayak, and P. K. Mohanty, 2015: Impacts of ENSO and IOD on tropical cyclone activity in the Bay of Bengal. Nat. Hazards, 75, 1105-1125, https://doi.org/10.1007/ s11069-014-1360-8.

Meng, W., and G. X. Wu, 2000: Gearing between the Indomonsoon circulation and the Pacific-Walker circulation and the ENSO. Part II: Numerical simulation (in Chinese). Chin. J. Atmos. Sci., 22, 470-480.

Meyers, G., P. McIntosh, L. Pigot, and M. Pook, 2007: The years of El Niño, La Niña, and interactions with the tropical Indian Ocean. J. Climate, 20, 2872-2880, https://doi.org/10.1175/ JCLI4152.1.

Murakami, H., and B. Wang, 2010: Future change of North Atlantic tropical cyclone tracks: Projection by a $20-\mathrm{km}-\mathrm{mesh}$ global atmospheric model. J. Climate, 23, 2699-2721, https:// doi.org/10.1175/2010JCLI3338.1.

Ng, E. K., and J. C. Chan, 2012: Interannual variations of tropical cyclone activity over the north Indian Ocean. Int. J. Climatol., 32, 819-830, https://doi.org/10.1002/joc.2304.

North, G. R., T. L. Bell, R. F. Cahalan, and F. J. Moeng, 1982: Sampling errors in the estimation of empirical orthogonal functions. Mon. Wea. Rev., 110, 699-706, https://doi.org/ 10.1175/1520-0493(1982)110<0699:SEITEO > 2.0.CO;2.

Rotunno, R., and K. A. Emanuel, 1987: An air-sea interaction theory for tropical cyclones. Part II: Evolutionary study using a nonhydrostatic axisymmetric numerical model. J. Atmos. Sci., 44, 542-561, https://doi.org/10.1175/15200469(1987)044<0542:AAITFT>2.0.CO;2.

Saji, N. H., B. N. Goswami, P. N. Vinayachandran, and T. Yamagata, 1999: A dipole mode in the tropical Indian Ocean. Nature, 401, 360-363, https://doi.org/10.1038/43854.

Schott, F. A., S. P. Xie, and J. P. McCreary, 2009: Indian Ocean circulation and climate variability. Rev. Geophys., 47, RG1002, https://doi.org/10.1029/2007RG000245.

Singh, O. P., 2008: Indian Ocean dipole mode and tropical cyclone frequency. Curr. Sci., 94, 29-31, https://www.jstor.org/stable/ 24102024
Smith, T. M., R. W. Reynolds, T. C. Peterson, and J. Lawrimore, 2008: Improvements to NOAA's historical merged landocean surface temperature analysis (1880-2006). J. Climate, 21, 2283-2296, https://doi.org/10.1175/2007JCLI2100.1.

Sumesh, K. G., and M. R. Kumar, 2013: Tropical cyclones over north Indian Ocean during El Niño Modoki years. Nat. Hazards, 68, 1057-1074, https://doi.org/10.1007/s11069-0130679-x.

Wang, B., and J. Y. Moon, 2017: An anomalous genesis potential index for MJO modulation of tropical cyclones. J. Climate, $\mathbf{3 0}$, 4021-4035, https://doi.org/10.1175/JCLI-D-16-0749.1.

Webster, P. J., A. M. Moore, J. P. Loschnigg, and R. R. Leben, 1999: Coupled ocean-atmosphere dynamics in the Indian Ocean during 1997-98. Nature, 401, 356-360, https://doi.org/ $10.1038 / 43848$

Werner, A., A. M. Maharaj, and N. J. Holbrook, 2012: A new method for extracting the ENSO-independent Indian Ocean dipole: Application to Australian region tropical cyclone counts. Climate Dyn., 38, 2503-2511, https://doi.org/10.1007/ s00382-011-1133-y.

Wu, G. X., and W. Meng, 1998: Gearing between the Indomonsoon circulation and the Pacific-Walker circulation and the ENSO. Part I: Data analyses (in Chinese). Chin. J. Atmos. Sci., 22, 470-480.

Xie, S. P., K. Hu, J. Hafner, H. Tokinaga, Y. Du, G. Huang, and T. Sampe, 2009: Indian Ocean capacitor effect on Indo-western Pacific climate during the summer following El Niño. J. Climate, 22, 730-747, https://doi.org/10.1175/ 2008JCLI2544.1.

Yanai, M., S. Esbensen, and J.-H. Chu, 1973: Determination of bulk properties of tropical cloud clusters from large-scale heat and moisture budgets. J. Atmos. Sci., 30, 611-627, https://doi.org/ 10.1175/1520-0469(1973)030<0611:DOBPOT > 2.0.CO;2.

Yuan, J. P., and J. Cao, 2013: North Indian Ocean tropical cyclone activities influenced by the Indian Ocean dipole mode. Sci. China Earth Sci., 56, 855-865, https://doi.org/10.1007/s11430012-4559-0.

Yuan, Y., and C. Li, 2008: Decadal variability of the IOD-ENSO relationship. Chin. Sci. Bull., 53, 1745-1752, https://doi.org/ 10.1007/s11434-008-0196-6. 